\title{
Influence of major fault zones on 3-D coupled fluid and heat transport for the Brandenburg region (NE German Basin)
}

\author{
Y. Cherubini ${ }^{1,2}$, M. Cacace $^{2}$, M. Scheck-Wenderoth ${ }^{2}$, and V. Noack ${ }^{2, *}$ \\ ${ }^{1}$ University of Potsdam, Institute of Earth and Environmental Science, Potsdam, Germany \\ ${ }^{2}$ Helmholtz Centre Potsdam - GFZ German Research Centre for Geosciences, Potsdam, Germany \\ *now at: Federal Institute for Geosciences and Natural Resources, Berlin, Germany
}

Correspondence to: Y. Cherubini (yvonne.cherubini@gfz-potsdam.de)

Received: 27 March 2013 - Revised: 29 January 2014 - Accepted: 26 February 2014 - Published: 4 April 2014

Abstract. To quantify the influence of major fault zones on the groundwater and thermal field, 3-D finiteelement simulations are carried out. Two fault zones - the Gardelegen and Lausitz escarpments - have been integrated into an existing 3-D structure of the Brandenburg region in northeastern Germany. Different geological scenarios in terms of modelled fault permeability have been considered, of which two end-member models are discussed in detail. In addition, results from these end-member simulations are compared to a reference case in which no faults are considered.

The study provides interesting results with respect to the interaction between faults and surrounding sediments and how it affects the regional groundwater circulation system and thermal field.

Impermeable fault zones seem to induce no remarkable effects on the temperature distribution; that is, the thermal field is similar to the no-fault model. In addition, tight faults have only a local impact on the fluid circulation within a domain of limited spatial extent centred on the fault zone. Fluid flow from the surrounding aquifers is deviated in close proximity of the fault zones acting as hydraulic barriers that prevent lateral fluid inflow into the fault zones.

Permeable fault zones induce a pronounced thermal signature with alternating up- and downward flow along the same structures. Fluid flow along the plane of the faults is principally driven by existing hydraulic head gradients, but may be further enhanced by buoyancy forces. Within recharge domains, fluid advection induces a strong cooling in the fault zones. Discharge domains at shallow depth levels $(\sim<-450 \mathrm{~m})$ are instead characterized by the presence of rising warm fluids, which results in a local increase of temperatures which are up to $15^{\circ} \mathrm{C}$ higher than in the no-fault case.

This study is the first attempt to investigate the impact of major fault zones on a 3-D basin scale for the coupled fluid and heat transport in the Brandenburg region. The approach enables a quantification of mechanisms controlling fluid flow and temperature distribution both within surrounding sediments and fault zones as well as how they dynamically interact. Therefore, the results from the modelling provide useful indications for geothermal energy exploration.

\section{Introduction}

Faults can significantly influence physical processes that control heat transfer and fluid motion in the subsurface. Faults provide permeable pathways for fluids at a variety of scales, from great depth in the crust to flow through fractured groundwater, geothermal and hydrocarbon reservoirs (Barton et al., 1995). Faults are also important because they may offset porous aquifer rocks against shales, rendering permeable rocks a dead end in terms of fluid flow (Bjørlykke, 2010). To understand the role of faults on the fluid and thermal field is 
also important for geothermal applications, as they may modify the overall reservoir permeability structure and therefore change its flow dynamics. Numerical simulations provide a useful tool for analysing heat and fluid transport processes in complex sedimentary basin systems integrating fault zones.

The aim of this study is to investigate the impact of major fault zones on the fluid and heat transport by 3-D numerical simulations. Our study is based on a recently published structural model of the Brandenburg area in the southeastern part of the Northeast German Basin (NEGB) (Noack et al., 2010). This refined 3-D structural model was constructed by integrating different types of data sets, including depth as well as thickness maps, data from previous models of the NEGB (Scheck and Bayer, 1999) and the Central European Basin System (Scheck-Wenderoth and Lamarche, 2005; Maystrenko et al., 2010), and well data (Noack et al., 2010). Subsequently, newly available data were integrated additionally to structurally refine the Tertiary unit (Noack et al., 2013). Figure 1 $a$ and $b$ outline the location of the study area and its present-day topographic elevation. The dominantly clastic sedimentary succession of the NEGB resolved in the model ranges from the Permian to Cenozoic and reaches up to $8000 \mathrm{~m}$ thick in the central part of the basin (Fig. 2a). In response to variations in lithologies, four aquitards of regional extent subdivide the sedimentary succession into different aquifer systems (Fig. 2b). These aquitard layers are from bottom to top, the Permian basement forming the lowermost impermeable layer in the model (Fig. 3a), the Upper Permian Zechstein salt (Fig. 3b), the Middle Triassic Muschelkalk limestones (Fig. 3c) and the Tertiary Rupelian clays (Fig. 3d). Model detailed information about the hydrogeological configuration of sedimentary layers of interest is given in Sect. 2.1.

Along the southern margin the basin is dissected by two major fault zones, the Gardelegen and Lausitz escarpments (Fig. 1b), which vertically offset the pre-Permian basement by several $\mathrm{km}$. As a result, the basement is uplifted by about $5 \mathrm{~km}$ coming close to the surface south of the Gardelegen Fault (Scheck-Wenderoth et al., 2008) (see also Fig. 3a).

The conductive thermal field of the Brandenburg region was first calculated by Noack et al. (2010, 2012). A comparison of the model results with published temperature measurements of 52 wells showed that the model predictions are largely consistent with the observations, indicating predominantly conductive heat transport (Noack et al., 2010, 2012). Local deviations between observations and model results were interpreted to be the result of additional fluidrelated processes. Indeed, recent 3-D coupled fluid and heat transport simulations have revealed that the shallow thermal field is influenced by forced convective processes due to hydraulic gradients (Noack et al., 2013). Another aspect that could be responsible for the deviations between observed and predicted temperatures are faults, which may provide pathways for moving fluids and which have been not included in the model (Noack et al., 2012, 2013).

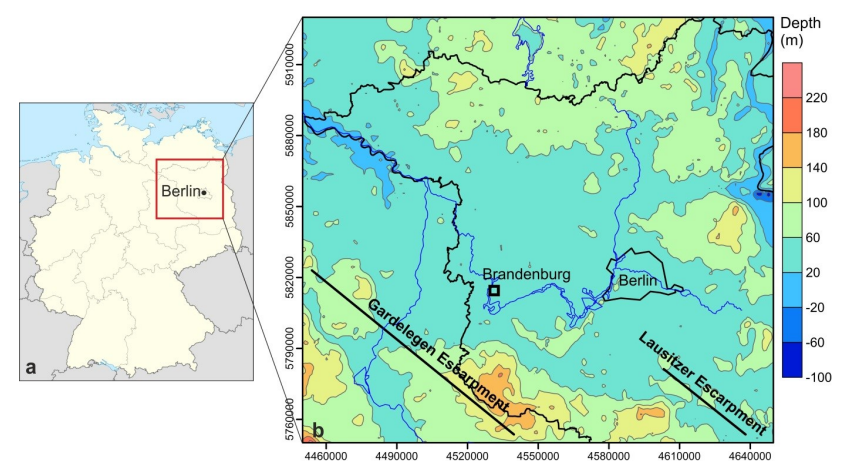

Figure 1. (a) Map of Germany showing the outlines of the study area located in the federal state of Brandenburg. The study area (red rectangle) covers a surface of $180 \mathrm{~km}$ in the $\mathrm{N}-\mathrm{S}$ direction and of $200 \mathrm{~km}$ in the E-W. (b) Topography map (top of Quaternary) of the model area in UTM zone $33^{\circ} \mathrm{N}$ (ETOPO1, after Amante and Eakins, 2009) with the borderline of Brandenburg (black solid line), main rivers (blue lines) and the location of the Gardelegen and Lausitz escarpments, which are part of the larger Elbe fault system. The approximated traces of these two major fault zones are given by the straight black solid lines.

These previous studies have provided deeper insights into the present-day thermal structure of the Brandenburg area. However, the impact that major existing fault zones may have on the groundwater system and thermal field has not been investigated so far. Previous 2-D numerical studies applied to different geological settings showed that faults may significantly influence the hydrothermal field (e.g. Bense et al., 2008; Garven et al., 2001; Lampe and Person, 2002; Magri et al., 2010; Simms and Garven, 2004; Yang et al., 2004a, b). These investigations demonstrated that along-fault convection may be an important heat transport mechanism in permeable faults and may give rise to significant variations of the thermal field. Results from 3-D studies seem to confirm these conclusions (Alt-Epping and Zhao, 2010; Bächler et al., 2003; Baietto et al., 2008; Cacace et al., 2013; Cherubini et al., 2013; López and Smith, 1995, 1996; Yang, 2006). However, differences between 2-D and 3-D studies have been found, due to the fact that the longitudinal fluid flow and heat transport along the strike of the faults are ignored in 2-D studies (Yang, 2006).

With the study area, previous attempts to investigate the influence of the Gardelegen fault zone have relied on 2-D coupled fluid and heat transport simulations. The study (Pommer, 2012) revealed a hydraulic interaction between shallow and deep aquifers in which upward convective and downward advective flow through the permeable fault coexist. The present study aims to upgrade the results obtained so far by assessing the influence of major fault zones on the 3-D basin scale. In the following, the results of the first 3-D hydrogeological model of the Brandenburg area that integrates two major fault zones and that couples transient fluid and heat 


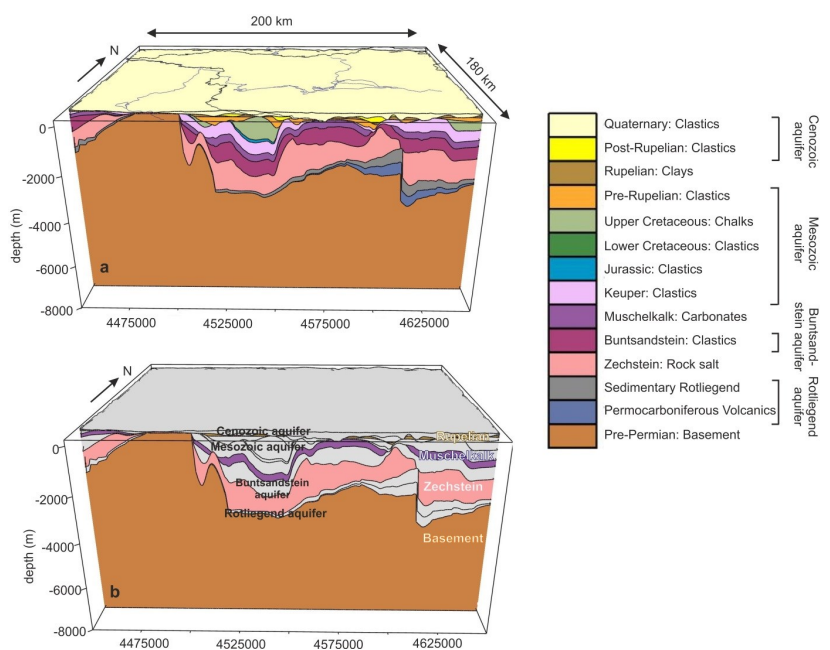

Figure 2. (a) Three-dimensional geological model of the study area with the stratigraphic layers resolved (vertical exaggeration: $7: 1$ ). Note the exposed pre-Permian basement coming close to the surface at the southeastern margin and the Permian Zechstein diapirs controlling the structural configuration of the overburden sediments. At the southern basin margin, the Gardelegen and Lausitz escarpments vertically offset the pre-Permian basement against the Permian to Cenozoic basin fill by several kilometres. (b) Distribution of aquitards and aquifers in the 3-D geological model (vertical exaggeration: $7: 1$ ). Four main layers act as regional barriers to fluid flow comprising the lowermost pre-Permian basement, the Permian Zechstein, the Middle Triassic Muschelkalk and the Tertiary Rupelian in the shallower part of the model. These aquitards hydraulically decouple the sedimentary succession into four main aquifer systems: from bottom to top, the Rotliegend aquifer, the Lower Triassic Buntsandstein aquifer, the Mesozoic aquifer and the Cenozoic aquifer.

transport in finite-element simulations are presented and discussed.

Due to variations in the regional stress field, different geological scenarios with an idealized fault zone representation in terms of their hydraulic behaviour have been tested, of which three end-member models are presented: (1) no fault (model 1), (2) tight fault zones (model 2) and (3) highly permeable fault zones (model 3). Model 1 is the reference case. It describes the "undisturbed" system with respect to the regional groundwater and thermal field. Thus, the regional thermal field is investigated by considering the interaction of different fluid and heat transport processes with respect to the hydrogeological setting of the study area. In model 2, a very low permeability is assigned for the faults zones, making them effectively impermeable for fluid flow. By contrast, in model 3, fault zones have a high permeability and are therefore supposed to act as hydraulically conductive structures. By means of these two end-member models, the influence of major fault zones on the coupled fluid and heat transport is quantified and the interaction between fault zones and surrounding sediments is addressed.

To assess the respective impact of the different faults on the thermal field and fluid circulation, the results of all three models are compared with each other and the outcomes are discussed.

\section{Data and method}

\subsection{Hydrogeological model}

The 3-D structural model covers an area of $200 \mathrm{~km}$ in E$\mathrm{W}$ and $180 \mathrm{~km}$ in $\mathrm{N}-\mathrm{S}$ direction reaching down to $-8000 \mathrm{~m}$ depth with a horizontal resolution of $1000 \mathrm{~m} \times 1000 \mathrm{~m}$, corresponding to $210 \times 180$ grid points. The model integrates 14 geological layers ranging from the pre-Permian basement at the bottom to the Quaternary at the top (Fig. 2a). In Table 1 all stratigraphic units are listed with predominant lithologies and corresponding physical properties adopted for the numerical simulations.

As summarized in Fig. 2b, the sedimentary succession is hydraulically decoupled by four regional aquitards (pre-Permian basement, Permian Zechstein, Middle Triassic Muschelkalk, Tertiary Rupelian) into four main aquifer systems (sedimentary Rotliegend, Lower Triassic Buntsandstein, Mesozoic aquifer, Cenozoic aquifer). The corresponding thickness maps for all aquitard layers are given in Fig. 3.

The lowermost, highly compacted pre-Permian represents the basement layer, which is assumed to be hydraulically impermeable due to its burial depth acting as the fourth major aquitard in the model (Fig. 2b and Table 1). The basement thickness gradually increases from northwest to southeast revealing up to $\sim 7000-8000 \mathrm{~m}$ thickness across the southern margin ("Flechtingen High") (Fig. 3a). It is followed upward by the Permo-Carboniferous volcanics and the clastic sedimentary Rotliegend, representing a prominent target horizon for geothermal exploration (e.g. Zimmermann et al., 2007). Evaporites, composed mainly of rock salt, form the overlying Permian Zechstein layer. The Zechstein salt layer represents the third regional aquitard in the model (Fig. 2b). Apart from its quasi-impermeable behaviour, rock salt has a relatively high thermal conductivity with respect to values for common sedimentary rocks (Table 1). Due to its thermal and fluid properties as well as its high level of geological structuration with up to 4500 thick salt diapirs locally piercing the overburden (Fig. 3b), this layer exerts a primary role in controlling the deeper groundwater circulation patterns and the thermal field. Above, the Lower Triassic Buntsandstein aquifer mainly consists of clastic sediments. Though limestones are the predominant lithology of the overlying Middle Triassic Muschelkalk, this layer acts as a second hydraulic barrier in the sedimentary succession, due to alternating anhydrite sequences (Fig. 2b and Table 1). In the central and northern parts of the study area, the Muschelkalk aquitard reaches down to $-4000 \mathrm{~m}$ depth, whereas it 

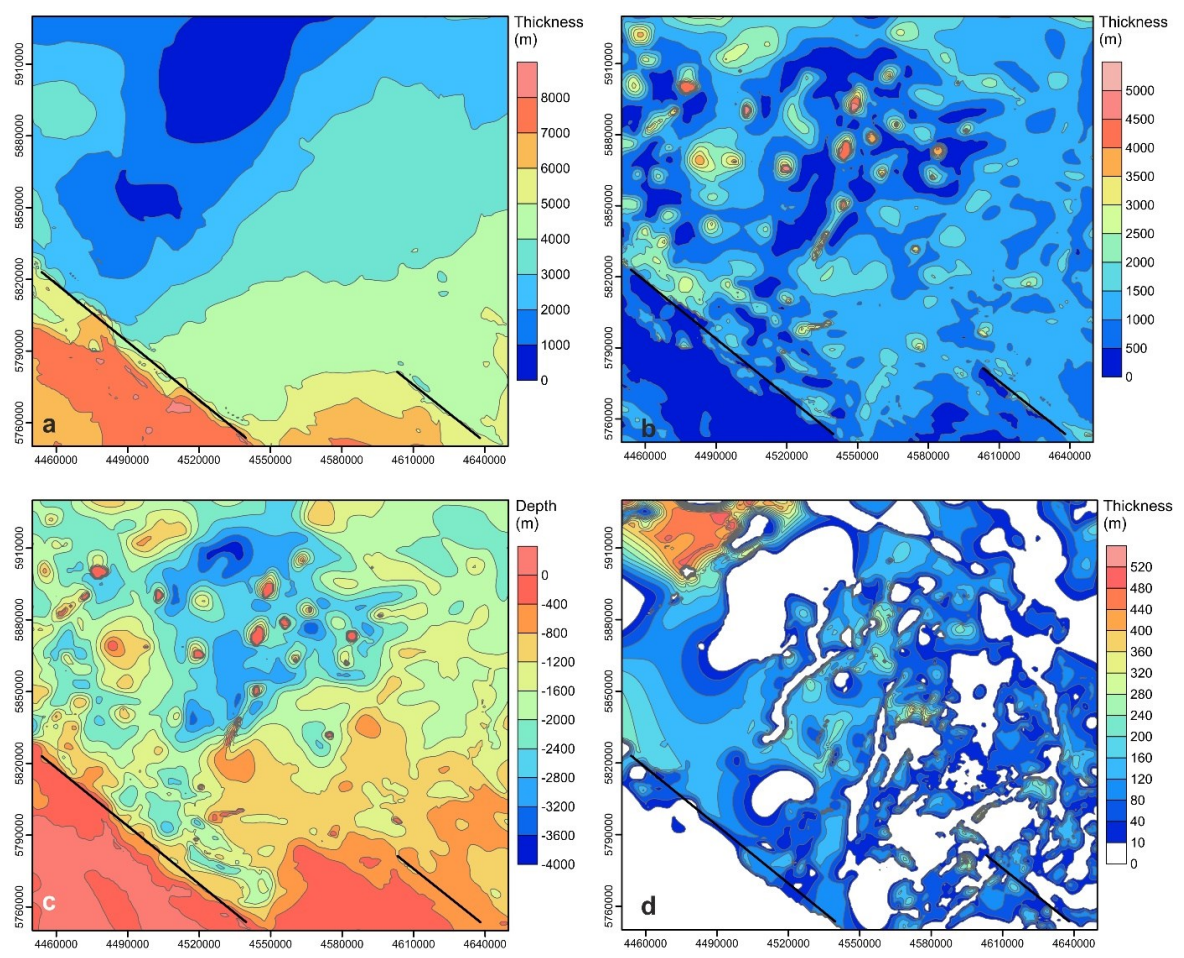

Figure 3. (a) Thickness map of the impermeable pre-Permian basement delineating the inverted southern margin where up to $\sim 8000 \mathrm{~m}$ thick basement comes close to the surface ("Flechtingen High"). The basement thickness thins abruptly near the large Gardelegen and Lausitz escarpments and gradually decreases north of these faults towards the basin centre. Location of the Gardelegen and Lausitz escarpments are given by the solid black lines (also in the following subfigures). (b) Map showing the highly variable thickness distribution of the Permian Zechstein, characterized by numerous salt pillows that can reach locally thicknesses of up to $4500 \mathrm{~m}$. Around the salt structures (salt rim synclines), reduced thicknesses indicate areas where the overburden Mesozoic and Cenozoic clastics reach their maximum thicknesses. (c) Depth of the top Middle Triassic Muschelkalk. This layer represents the lower limit of the Mesozoic aquifer. (d) Thickness map of the Tertiary Rupelian aquitard revealing large geological windows where this clay-rich layer was not deposited or has been eroded.

comes close to the surface at the southern margin (Fig. 3c). The Muschelkalk aquitard is followed upward by the clastic Upper Triassic Keuper, Jurassic, and Lower and Upper Cretaceous layers, together forming the Mesozoic aquifer complex. The clastic Tertiary overlays the Mesozoic aquifer complex. The Tertiary has been resolved into post-Rupelian, Rupelian and pre-Rupelian sub-units. Of these, the clay-rich Rupelian unit is characterized by a very low permeability (Table 1), thus representing the shallowest hydraulic barrier in the sedimentary succession separating the Quaternary and Tertiary units from the deeper aquifers (Figs. $2 b$ and $3 d$ ) (cf. Hebig et al., 2012). Over most part of the study area, the thickness of the Rupelian clay varies between $\sim 0$ and $280 \mathrm{~m}$; only the northwestern part is characterized by a higher thickness up to $\sim 520 \mathrm{~m}$ (Fig. 3d). Areas where the Rupelian clay has not been deposited or eroded, "Rupelian windows", hydraulically connect the Mesozoic aquifer with the shallow Cenozoic aquifer complex. The latter is formed by the postRupelian and the uppermost Quaternary layer consisting of unconsolidated, permeable sediments.

\subsection{Fault system}

The Gardelegen and Lausitz escarpments are two major WNW-ESE-striking structures of the larger Elbe fault system (EFS). The EFS encompasses an approximately $800 \mathrm{~km}$ long, WNW-ESE-striking zone extending from the southeastern North Sea to southwestern Poland along the present southern margin of the North German and Polish basins (Scheck et al., 2002). During a Late Cretaceous-early Cenozoic compressional event induced by the Alpine convergence and by the opening of the North Atlantic Ocean, individual faults of the EFS in northern Germany were reactivated to a certain extent as thrust or transpressional faults. Along these faults vertical offsets may reach several kilometres (Scheck et al., 2002). As part of these reactivated structures, the Gardelegen and Lausitz fault zones sub-vertically cut through all sedimentary layers in the structural model and offset the uplifted pre-Permian basement (Flechtingen High) across the southern margin by up to $4 \mathrm{~km}$ against the Permian to Cenozoic sedimentary succession.

Faults' orientation within the present-day stress field is a primary factor controlling their hydraulic behaviour with 
Table 1. Stratigraphic units with predominant lithologies and corresponding physical properties used for the numerical simulations. Hydrogeological barriers separating the stratigraphic succession into different aquifer systems are highlighted (bold).

Porosity and heat capacity after Magri (2005). Permeability values assigned for the Cenozoic (post-Rupelian, Rupelian, pre-Rupelian and Quaternary) after Noack et al. (2013), and for the Mesozoic and Palaeozoic after Magri (2005).

Thermal conductivity and radiogenic heat production used for numerical simulations of the thermal field for the Brandenburg area: thermal conductivities and radiogenic heat production after Bayer et al. (1997), thermal properties for post-Rupelian, Rupelian and pre-Rupelian after Noack et al. (2013) and radiogenic heat production of Rupelian after Balling et al. (1981).

\begin{tabular}{|c|c|c|c|c|c|}
\hline $\begin{array}{l}\text { Stratigraphic unit } \\
\text { (predominant } \\
\text { lithologies) }\end{array}$ & $\begin{array}{l}\text { Permeability } \\
\kappa\left[\mathrm{m}^{2}\right]\end{array}$ & $\begin{array}{l}\text { Porosity } \\
\varepsilon[\%]\end{array}$ & $\begin{array}{l}\text { Rock heat capacity } \\
c_{\mathrm{s}}\left[\mathrm{MJ} \mathrm{m}^{-3} \mathrm{~K}^{-1}\right]\end{array}$ & $\begin{array}{l}\text { Bulk thermal } \\
\text { conductivity } \\
\lambda\left[\mathrm{W} \mathrm{m}^{-1} \mathrm{~K}^{-1}\right]\end{array}$ & $\begin{array}{l}\text { Radiogenic heat } \\
\text { production } \\
Q_{T}\left[10^{-7} \mathrm{~W} \mathrm{~m}^{-3}\right]\end{array}$ \\
\hline $\begin{array}{l}\text { Quaternary } \\
\text { (sand, silt, clay) }\end{array}$ & $1.0 \times 10^{-13}$ & 23 & 3.15 & 1.5 & 7 \\
\hline $\begin{array}{l}\text { Post-Rupelian } \\
\text { (sand, silt, clay) }\end{array}$ & $1.0 \times 10^{-14}$ & 23 & 3.15 & 1.5 & 7 \\
\hline $\begin{array}{l}\text { Rupelian } \\
\text { (clay) }\end{array}$ & $1.0 \mathrm{E}-16$ & 20 & 3.3 & 1.0 & 4.5 \\
\hline $\begin{array}{l}\text { Pre-Rupelian } \\
\text { (sand, silt, clay) }\end{array}$ & $1.0 \times 10^{-14}$ & 10 & 2.4 & 1.9 & 3 \\
\hline $\begin{array}{l}\text { Upper Cretaceous } \\
\text { (chalk) }\end{array}$ & $1.0 \mathrm{E}-13$ & 10 & 2.4 & 1.9 & 3 \\
\hline $\begin{array}{l}\text { Lower Cretaceous } \\
\text { (clays with sand and } \\
\text { silt) }\end{array}$ & $1.0 \times 10^{-13}$ & 13 & 3.19 & 2.0 & 14 \\
\hline $\begin{array}{l}\text { Jurassic } \\
\text { (clays with sand, silt, } \\
\text { marl) }\end{array}$ & $1.0 \times 10^{-13}$ & 13 & 3.19 & 2.0 & 14 \\
\hline $\begin{array}{l}\text { Keuper } \\
\text { (clays with marl and } \\
\text { gypsum) }\end{array}$ & $1.0 \times 10^{-14}$ & 6 & 3.19 & 2.3 & 14 \\
\hline $\begin{array}{l}\text { Muschelkalk } \\
\text { (limestone) }\end{array}$ & $1.0 \mathrm{E}-18$ & 0.1 & 2.4 & 1.85 & 3 \\
\hline $\begin{array}{l}\text { Buntsandstein } \\
\text { (silts with sand, clay, } \\
\text { evaporite) }\end{array}$ & $1.0 \times 10^{-14}$ & 4 & 3.15 & 2.0 & 10 \\
\hline $\begin{array}{l}\text { Zechstein } \\
\text { (evaporites) }\end{array}$ & $\begin{array}{l}\text { Impermeable } \\
\sim 0\end{array}$ & $\sim 0$ & 1.81 & 3.5 & 0.9 \\
\hline $\begin{array}{l}\text { Sedimentary } \\
\text { Rotliegend } \\
\text { (clay, silt, sandstone) }\end{array}$ & $1.0 \times 10^{-14}$ & 0.3 & 2.67 & 2.16 & 10 \\
\hline $\begin{array}{l}\text { Permo-Carboniferous } \\
\text { volcanics (rhyolite and } \\
\text { andesite) }\end{array}$ & $1.0 \mathrm{E}-14$ & 0.3 & 2.67 & 2.5 & 20 \\
\hline $\begin{array}{l}\text { Pre-Permian } \\
\text { basement }\end{array}$ & $\begin{array}{l}\text { Impermeable } \\
\sim 0\end{array}$ & $\sim 0$ & 2.46 & 2.65 & 15 \\
\hline
\end{tabular}

critically stressed faults acting as highly permeable hydraulic conduits and non-critically stressed faults acting as hydraulic barriers (Barton et al., 1995). Therefore, a characterization of hydraulic properties of the faults integrated in the model could be achieved via a previous knowledge of the presentday in situ stress field.
The present-day regional stress field in Germany and surrounding regions as summarized by the most recent release of the World Stress Map shows a broad-scale NW-SE direction of the maximum horizontal stress $S_{\text {Hmax }}$ in the western part with a rotation toward NE-SW in the easternmost part of the region (World Stress Map, 2000, and references therein). Borehole stress data show a different orientation of $S_{\mathrm{Hmax}}$ 
in the suprasalt and subsalt complexes (Roth and Fleckenstein, 2001). Subsalt in situ stress data show a more uniform $S_{\text {Hmax }}$ orientation with an approximate $\mathrm{N}-\mathrm{S}$ direction opening to a more NE-SW direction in the eastern parts of the basin (Marotta et al., 2002; Cacace et al., 2008). In contrast, the stress field in the suprasalt is highly inhomogeneous and shows no dominant direction of the maximum component (Röckel and Lempp, 2003).

From what has been stated above, no simple relationship between in situ stress field and fault pattern can be obtained. In order to represent the different possible stress states, various geological scenarios have been tested, of which two endmember models are represented: (1) fault zones are considered as barriers to fluid flow because they are non-critically stressed (model 2), and (2) fault zones are supposed to act as hydraulically conductive structures because they are critically stressed (model 3). In addition, a simulation in which no fault is included is also presented (model 1). Simulation results of the two fault models (model 2 and model 3) are then compared to the no-fault case (model 1) to quantify their respective impact on the coupled fluid and heat transport.

\subsection{Set-up of the numerical model}

Three-dimensional coupled fluid and heat transport simulations are carried out with the numerical simulator FEFLOW ${ }^{\circledR}$ (Diersch, 2002). This commercial software package is based on the finite-element method (FEM) and enables the modelling of coupled fluid flow and transport processes in variably saturated porous media. The governing equations of density coupled thermal convection in saturated porous media are given in Appendix A.

Within coupled simulations, different fluid and heat transfer processes are taken into account, including conduction, convection and advection.

Conductive heat transfer occurs due to an existing temperature gradient through rock molecules transmitting their kinetic energy by collision (Turcotte and Schubert, 2002). The flow of heat is directly proportional to the existing temperature gradient via the medium bulk thermal conductivity (see Eq. 3).

Heat transport by moving fluids includes convection and advection. Convective heat transport is a form of buoyant flow due to differences in fluid temperature (or salinity), whereas advection is triggered by gradients in the hydraulic head inducing flow from higher to lower hydraulic potentials (Bjørlykke, 2010). For the present study, only temperatureinduced density changes of the fluid are considered and the influence of salinity of the fluid is neglected within the simulations. Mixed convection is the result of all these different fluid and heat transfer processes acting on the same geological system.

\subsubsection{FEM model construction}

In order to build the FEM, the outlines of the study area $(180 \mathrm{~km} \times 200 \mathrm{~km})$ need to be defined as a "super-element" in FEFLOW ${ }^{\circledR}$. To integrate the faults into the model, two lines representing the approximated traces of the fault zones are implemented into the super-element. Within its frame, a two-dimensional unstructured triangle mesh is then generated, referred to as a "reference slice". To build up a 3D model, copies of the reference slice (all with the same horizontal mesh resolution) are vertically connected at each nodal point of the mesh. One geological layer is represented by the 3-D body between a top and a bottom slice. From the number of 14 geological layers, 15 slices are required to construct the 3-D model. To reproduce the geological subsurface structure, the geometry of the stratigraphic layers is derived from the structural model (Fig. 2a). The extracted $z$ coordinates (elevations) of each geological top and base surface are assigned to each node of the corresponding top and bottom slice in the numerical model. Therefore, the resulting layer thicknesses a priori determine the vertical resolution of the numerical model. To guarantee numerical stability, the vertical resolution of the model is refined by subdividing all layers into two sub-layers each. The model is closed along its base by inserting a planar slice at a constant depth of $-8000 \mathrm{~m}$.

According to the main lithology of each geological unit, hydraulic and thermal rock properties are assigned to each corresponding layer in the numerical model (Tables 1). Each layer is considered homogenous and isotropic with respect to its physical properties.

Permeable fault zones are implemented as a combination of discrete feature elements and equivalent porous media. Discrete feature elements are finite elements of lower dimensionality, which can be inserted at element edges and faces (Diersch, 2002). We use vertical 2-D discrete elements and assume Darcy's law as governing law of fluid motion within the fault elements as well. A highly permeable (permeability equal to that of the discrete fault) domain extending for $500 \mathrm{~m}$ on either side of the fault trace has been additionally integrated. This domain surrounding the discrete fault elements has been locally refined to ensure a stable calculation of the simulated physical processes. Mesh resolution within this domain is approximately $100 \mathrm{~m}$. Impermeable faults are modelled as equivalent porous media having a lateral extent of $1 \mathrm{~km}$, i.e. equal to the permeable fault zones case.

The final 3-D finite-element model consists of 28 layers (accordingly 29 slices) with approximately 3.5 million elements (i.e. triangulated prisms).

Table 2 summarized the fault properties adopted in the two model realizations. 
Table 2. Thermal and hydraulic properties used for the fault modelling.

\begin{tabular}{lll}
\hline Properties & $\begin{array}{l}\text { Faults - } \\
\text { impermeable } \\
\text { (model 2) }\end{array}$ & $\begin{array}{l}\text { Faults - } \\
\text { permeable } \\
\text { (model 3) }\end{array}$ \\
\hline $\begin{array}{l}\text { Porosity } \varepsilon[\%] \\
\begin{array}{l}\text { Rock heat } \\
\text { capacity } c_{\mathrm{s}}\left[\mathrm{M} \mathrm{J} \mathrm{m}^{-3} \mathrm{~K}^{-1}\right]\end{array}\end{array}$ & $\sim 0$ & $30^{1}$ \\
Bulk thermal conductivity & $2.6^{2}$ & $2.49^{1}$ \\
$\lambda\left[\mathrm{W} \mathrm{m}^{-1} \mathrm{~K}^{-1}\right]$ & $2.63^{1}$ \\
$\begin{array}{l}\text { Permeability } \kappa\left[\mathrm{m}^{2}\right] \\
\text { Radiogenic heat }\end{array}$ & $\sim 0$ & $1 \times 10^{-12^{1}}$ \\
$\begin{array}{l}\text { Production } \\
Q_{T}\left[10^{-7} \mathrm{~W} \mathrm{~m}^{-3}\right]\end{array}$ & $0.9^{2}$ & $0.89^{1}$ \\
\hline
\end{tabular}

${ }^{1}$ Values after Pommer (2012); ${ }^{2}$ mean values of the geological layers averaged by their thicknesses.

\subsubsection{Time setting}

Though the present study aims to address the present-day state, transient coupled simulations for all models are run for 250000 years. This is done to let the system equilibrate, thus obtaining pseudo-steady-state conditions. Given the goal of the study, results are shown only for the final simulation state at 250000 years.

\subsubsection{Boundary and initial conditions}

A fixed hydraulic head equal to the topographic elevation is assigned at the top of the model. Due to this upper flow boundary condition, groundwater flow is predominantly controlled by gradients in the topography. No-flow boundary conditions are set along the bottom and lateral boundaries of the model.

As upper thermal boundary condition, we assume a fixed constant surface temperature of $8^{\circ} \mathrm{C}$, according to the average surface temperature in northeastern Germany (Diener et al., 1984). At the model base ( $-8000 \mathrm{~m}$ depth), a variable temperature distribution is defined which has been extracted from a lithosphere-scale conductive thermal model of Brandenburg taking into account the thermal effects of the underlying differentiated crust and lithosphere, down to a depth of $-125 \mathrm{~km}$ (Noack et al., 2012). Figure 4 illustrates the variations imposed to the bottom thermal boundary. Highest temperatures $\left(\sim 260-285^{\circ} \mathrm{C}\right)$ characterize the southern and eastern area. Furthermore, temperatures increase up to $\sim 275^{\circ} \mathrm{C}$ along the western margin. By contrast, lowest temperatures are present at the southern margin (down to $220^{\circ} \mathrm{C}$ ) and in the northern and northwestern model area. The regional temperature field at this depth is predominantly controlled by the thickness distribution of the underlying upper crust (characterized by higher values of thermal conductivity and radiogenic heat production) and of the low conductive post-salt deposits (Noack et al., 2012).

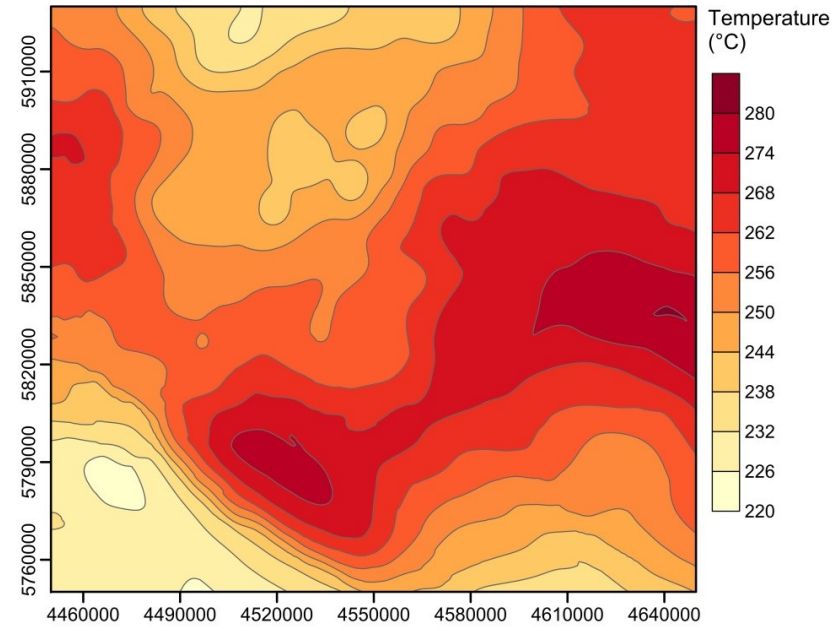

Figure 4. Laterally variable temperature distribution at $-8000 \mathrm{~m}$ depth used as the lower thermal boundary condition for all numerical simulations presented in the manuscript. The distribution has been extracted from a lithosphere-scale conductive thermal model of Brandenburg by Noack et al. (2012).

Initial pressure and temperature conditions are derived from steady-state uncoupled flow and heat transport simulations, respectively.

\section{Modelling results}

\subsection{Regional thermal field}

A preliminary investigation of the regional thermal field at different depth levels enables a first assessment to be carried out of the temperature distribution with respect to the regional hydrogeological setting. This evaluation is necessary to quantify more completely the influence of the fault configurations on the fluid and thermal regime. Therefore, in the following Sects. 3.1.1 and 3.1.2, the results of model 1 in which no fault is included are first discussed and then subsequently compared to the simulation results of the two fault models (model 2 and model 3).

Figures 5a displays the horizontal temperature distribution at $-1000 \mathrm{~m}$ depth for model 1 (no faults). The results for model 2 (impermeable fault zones) and model 3 (permeable fault zones) are shown in Fig. 5b and c, respectively. The depth level of $-1000 \mathrm{~m}$ is located below the Tertiary Rupelian aquitard and cuts through the pre-Rupelian Mesozoic aquifer as well as the pre-Permian basement along the southern margin of the basin (Figs. 2b and 3d). The temperature maps at $-3000 \mathrm{~m}$ depth of model 1 (Fig. 5d), model 2 (Fig. 5e) and model 3 (Fig. 5f) cut through the Mesozoic sediments, major Permian salt diapirs and the pre-Permian basement at the southern margin (cf. Fig. 3c and d). 

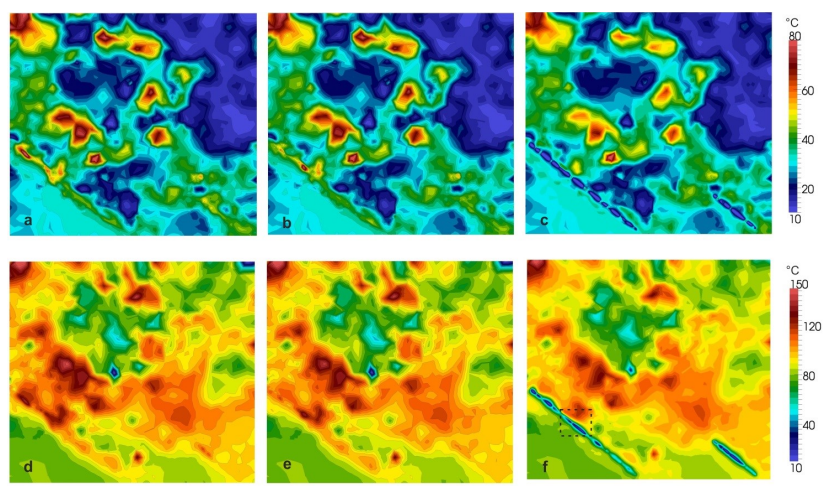

Figure 5. (a-c) Temperature distribution along a horizontal slice at $-1000 \mathrm{~m}$ depth cutting the (a) no-fault model (model 1), (b) impermeable fault model (model 2) and (c) permeable fault model (model 3). (d-f) Temperature distribution along a horizontal slice at $-3000 \mathrm{~m}$ depth cutting the (d) no-fault model (model 1), (e) impermeable fault model (model 2) and (f) permeable fault model (model 3 ). In (f) the black rectangle displays the position of the map view in Fig. 10b. All temperature maps encompass the complete model domain. Note the significant difference in the modelled temperatures in the proximity of the faults for model 3 compared to the very similar model 1 and model 2.

\subsubsection{Horizontal temperature distribution: $-1000 \mathrm{~m}$ depth}

At $-1000 \mathrm{~m}$ depth, temperatures range between $\sim 30$ and $50{ }^{\circ} \mathrm{C}$ in wide parts of the study area. Local spots of higher temperatures (up to $80^{\circ} \mathrm{C}$ ) are also visible in the western and central domains (Fig. 5a). Across the southern margin of the basin, temperatures are sensitively lower $\left(\sim 22-34^{\circ} \mathrm{C}\right)$ and are even colder in larger parts of the north and northeastern model area $\left(10-20^{\circ} \mathrm{C}\right)$.

The regional temperature pattern can be correlated to the thickness of the overlying Rupelian aquitard (Fig. 3d). Locations where the Rupelian clay is missing (Rupelian windows) correspond to areas of strongly reduced temperatures. The reason for the observed cooling trend should be related to cold water inflow from the top surface (set to $8^{\circ} \mathrm{C}$ ) which penetrates unhampered into deeper parts of the model, thus leading to the modelled cooling within the Mesozoic aquifer (cf. Fig. 2b). Higher topographic elevations (recharge areas) above these Rupelian windows (cf. Fig. 1b) enhance cold water advection and hence the observed cooling.

However, local spots of distinctly higher temperatures in the western and central domains can be correlated with areas with an increased thickness of the Rupelian aquitard, which prevents cold water inflow from the surface to reach this depth levels (cf. Fig. 3d). As a consequence, significantly higher temperatures are generated below the Rupelian. At these locations, temperatures additionally increase in the vicinity of major Zechstein salt diapirs (Fig. 3b) due to the thermal blanketing effect by thick and low conductive Mesozoic sediments.
Across the southern margin, larger areas of lower temperatures correspond to domains in which the pre-Permian basement almost reaches the surface (Flechtingen High) (Fig. 3a). The thick impermeable and thermally highly conductive basement leads to very efficient conductive heat transport towards the surface. Due to the absence of overlying sediments, heat cannot be stored by thermal blanketing and gets lost at the surface, thus explaining the observed thermal trend along the margin of the basin (cf. Fig. 2a).

\subsubsection{Horizontal temperature distribution: $-3000 \mathrm{~m}$ depth}

At $-3000 \mathrm{~m}$ depth the thermal field shows a wider range of variations with respect to the shallower temperature distribution described above. At this depth level, modelled temperatures vary between minima of approximately $10^{\circ} \mathrm{C}$ and maxima of up to $150^{\circ} \mathrm{C}$ (Fig. 5d). Local spots of reduced temperatures $\left(\sim 44-52^{\circ} \mathrm{C}\right)$ occur in the central and northwestern parts. As already observed at $-1000 \mathrm{~m}$ depth, the southern margin is characterized by relatively lower temperatures with respect to the central domains $\left(\sim 80^{\circ} \mathrm{C}\right)$. Higher temperatures of up to $150^{\circ} \mathrm{C}$, however, occur in the western, northwestern, eastern and central parts. These positive thermal anomalies show both short-wavelength ("spot-like anomalies") and long-wavelength ("elongated anomalies") characteristic geometries.

The occurrence of local negative thermal anomalies in the central and northwestern domains can be structurally linked to the topology of the Rupelian aquitard and of the Middle Triassic Muschelkalk aquitard, the latter limiting the Mesozoic aquifer at its base (Fig. 3c). Indeed, cooler temperatures are present in areas where the Mesozoic aquifer reaches deeper than $-3000 \mathrm{~m}$ beneath major hydraulic windows in the Rupelian thickness distribution (cf. Fig. 3a and b). Therefore, cold water from the top surface can flow downward and penetrate to greater depths.

The long term spatial distribution of modelled temperature in the remaining part of the study area is mainly controlled by the geometry and thickness of the pre-Permian basement (Fig. 3a). Reduced temperatures are present across the southern margin, where the basement reaches its highest thickness and shallowest depths. Similar to the thermal pattern at $-1000 \mathrm{~m}$ depth, heat loss is caused by the lack of insulating cover sediments. By contrast, domains of increased temperatures in the basin centre evolve beneath a thick basement overlain by a thick sequence of Mesozoic sediments that act as a thermal blanket.

Additionally, temperatures rise in the vicinity of major salt diapirs (spot-like anomalies). These are locations where low conductive Mesozoic and Cenozoic sediments reach their highest thicknesses and hence where their thermal blanketing effect is most effective.

From the results described above it can be concluded that the temperature distribution is the result of superposed thermal effects generated by the complex interaction between the 
hydrodynamics induced by the boundary settings and the hydrogeological configuration of the basin comprising different sediment types as (a) the permeable but thermally insulating Mesozoic sediments, (b) the intercalated but partially discontinuous aquitards (Rupelian and Middle Triassic Muschelkalk) (c) the impermeable but thermally conductive Zechstein salt and (d) the pre-Permian basement.

Modelled temperature distributions for model 2 (impermeable faults) show a striking resemblance with those obtained for model 1 (no faults) both at -1000 and $-3000 \mathrm{~m}$ depth (Fig. $5 \mathrm{~b}$ and e). In order to quantify the range of magnitudes of calculated differences between the two model realizations, as well as their spatial correlation, contour maps of temperature differences between model 1 and 2 are shown in Fig. 6a $(-1000 \mathrm{~m}$ depth) and Fig. $6 \mathrm{~b}(-3000 \mathrm{~m}$ depth). A close inspection of these two figures reveals only minor temperature differences (maximum about $10 \mathrm{~K}$ ), which spatially correlate with the location and geometry of the two fault zones. The localized temperature differences and the overall similarity to the no-fault scenario indicate that the impermeable fault zones only have a minor influence on the thermal field. Adding to this first conclusion, it is worth emphasizing that the areas affected by the presence of the fault zones can be further used to spatially constrain what we from here on refer to as the "range of influence" of the two faults on the regional thermal pattern and groundwater dynamics. Such a range of influence is found to vary between the two fault zones $(10 \mathrm{~km}$ for the Gardelegen Escarpment and $4 \mathrm{~km}$ for the Lausitzer Escarpment). This last aspect can be related to existing differences in geometry and spatial extension between the two faulted areas - an observation that clearly points toward the presence of a thermal and pressure field - which are structurally controlled by the local fault configuration cutting through the sedimentary sequence.

At $-1000 \mathrm{~m}$ depth, model 3 (highly permeable faults) shows distinctly cooler temperatures $\left(10-35^{\circ} \mathrm{C}\right)$ along both fault zones with an alternating thermal signature (Fig. 5c). A temperature difference map between model 1 (no faults) and model 3 shows differences of $\sim 20$ to $80 \mathrm{~K}$ at the permeable fault zones (Fig. 6c). As found for model 2, the range of influence varies between the two fault areas, at the Lausitzer fault zone ranging between $\sim 3.5$ and $7.4 \mathrm{~km}$ and that at the Gardelegen fault zone between $\sim 2.4$ and $8.8 \mathrm{~km}$.

Spatial variations in the extent of the range of influence for a single fault zone are structurally related to the presence of differing sedimentary layers bordering the fault zone. The range of influence is decreased in areas where the fault zone is bordered the pre-Permian, Zechstein and Muschelkalk aquitards. Due to their hydraulically impermeable setting, heat is transferred only by diffusion within these layers, thus leading to a less effective propagation of thermal anomalies far from the fault domains. By contrast, the range of influence is increased in those areas where the fault zones are next to aquifers because the heated fluid can spread out into
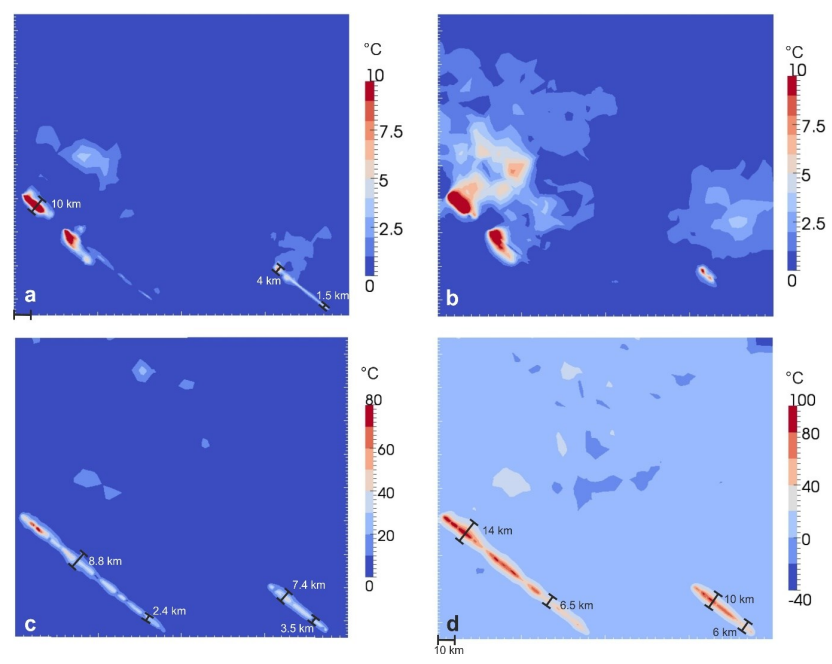

Figure 6. (a-b) Temperature difference maps between no-fault model 1 and impermeable fault model 2 at (a) $-1000 \mathrm{~m}$ depth and (b) at $-3000 \mathrm{~m}$ depth. (c-d) Temperature difference maps between no-fault model 1 and permeable fault model 3 at (c) $-1000 \mathrm{~m}$ depth and (d) at $-3000 \mathrm{~m}$ depth. Positive values indicate higher temperatures in the no-fault model and vice versa. Local temperature differences (maximum $10 \mathrm{~K}$ ) indicate that the impermeable fault zones slightly affect the temperature distribution. By contrast, the permeable fault zones exert a significant influence on the thermal field, reflected by distinctly cooler temperatures (of maximum $100 \mathrm{~K}$ ) that characterize the internal parts of the fault zones.

the permeable sediments, reaching greater distances within the layers.

Differences in the local thermal field can also be observed at $-3000 \mathrm{~m}$ depth between model 3 and model 1 (Fig. 5f). Along the fault planes, isotherms are arranged in an alternating pattern, displaying values between 10 and $56^{\circ} \mathrm{C}$. At these locations temperatures are about 35-45 K (maximum $100 \mathrm{~K}$ ) lower than those obtained for model 1 (no faults) (Fig. 6d). The total range of influence varies between $\sim 6$ and $10 \mathrm{~km}$ for the Lausitz fault zone and between $\sim 6.5 \mathrm{~km}$ and $14 \mathrm{~km}$ for the Gardelegen fault zone.

Moving away from the fault zones, the three models show the same regional trend in the resulting thermal field. These similarities found in the regional thermal configuration should be considered as an additional indication of the sub-regional influence exerted by the two fault zones. Indeed, considering a different fault configuration does not seem to alter the main physical processes driving thermal and groundwater transport in the sedimentary compartments away from the faults' range of influence proper.

By looking at Fig. 6 it can be noticed that despite a very similar regional thermal trend between all three models, differences are found in computed magnitudes at greater distance from the fault zones.

In the case of model 1 (no faults) minus model 2 (impermeable fault zones), these differences range between 1 and 
maximum $8 \mathrm{~K}$ and are spatially constrained to spots of relatively small extent in the centre of the model domain north of the two fault zones (Fig. 6a and b). In the case of model 1 (no faults) minus model 3 (permeable fault zones), spots of temperature differences are confined to the central and northern model domain at $-1000 \mathrm{~m}$ depth (Fig. 6c). At $-3000 \mathrm{~m}$ depth, temperatures locally differ from the no-fault model in the central domain $(-20$ to $20 \mathrm{~K})$ as well as at the NE edge (up to $-40 \mathrm{~K}$ ) (Fig. 6d).

In this regard it is worth mentioning that the three models differ only with respect to the adopted parameterization considered for representing the two fault zones. Accordingly, the observed local variations in magnitudes result from having different model configurations. Indeed, all simulations are performed considering the system thermodynamically closed, which in turn requires an overall conservation of the internal energy of the system. As the boundary conditions are the same in all three simulations, changes implemented for the domains of the fault zones will also cause differences for the remaining model domain in response to mass- and energy conservation. Therefore, local changes in magnitudes of the temperature field as observed in these areas far away from the fault zones are the consequence of the differences in model configuration. These differences can be considered as a physical sound consequence of variations in the groundwater dynamics and related thermal field due to different hydrogeological characteristics for the three models. Following this reasoning, it naturally follows that the greatest differences in magnitude of modelled temperatures are to be expected for those simulations which differ the most. Indeed, the largest difference is between model 1 and model 3 (Fig. 6c and d).

\subsection{Temperature distribution in the fault zones}

To understand the pronounced thermal signature within both permeable faults (model 3), a more detailed analysis of the thermal state along the entire fault zones is carried out. Figure 7a displays the temperature distribution along the Gardelegen and Lausitz fault zones. Temperatures range between 8 and $75^{\circ} \mathrm{C}$ along both faults. Convex upward-shaped isotherms (corresponding to temperatures as high as 35$75^{\circ} \mathrm{C}$ ) alternate with isotherms that are bent convexly downward (indicating temperatures as low as $8-30^{\circ} \mathrm{C}$ ). This alternating temperature pattern reflects thermal anomalies already described in the regional thermal field at -1000 and $-3000 \mathrm{~m}$ depth along the permeable fault zones (Fig. $5 \mathrm{c}$ and f).

A combination plot of isotherms and fluid velocity vectors along the Gardelegen Fault (similar conclusions are also valid for the Lausitz fault zone) shows that convex downward-shaped isotherms (cold domains) correspond to relatively fast downward groundwater flow $\left(\sim 1 \times 10^{-2}\right.$ $3 \times 10^{-2} \mathrm{~m} \mathrm{~d}^{-1}$ ) (Fig. 7b). By contrast, convex upward-bent isotherms conform to mainly upward groundwater flow of lower fluid velocities $\left(\sim 1 \times 10^{-4}-1 \times 10^{-3} \mathrm{~m} \mathrm{~d}^{-1}\right)$.

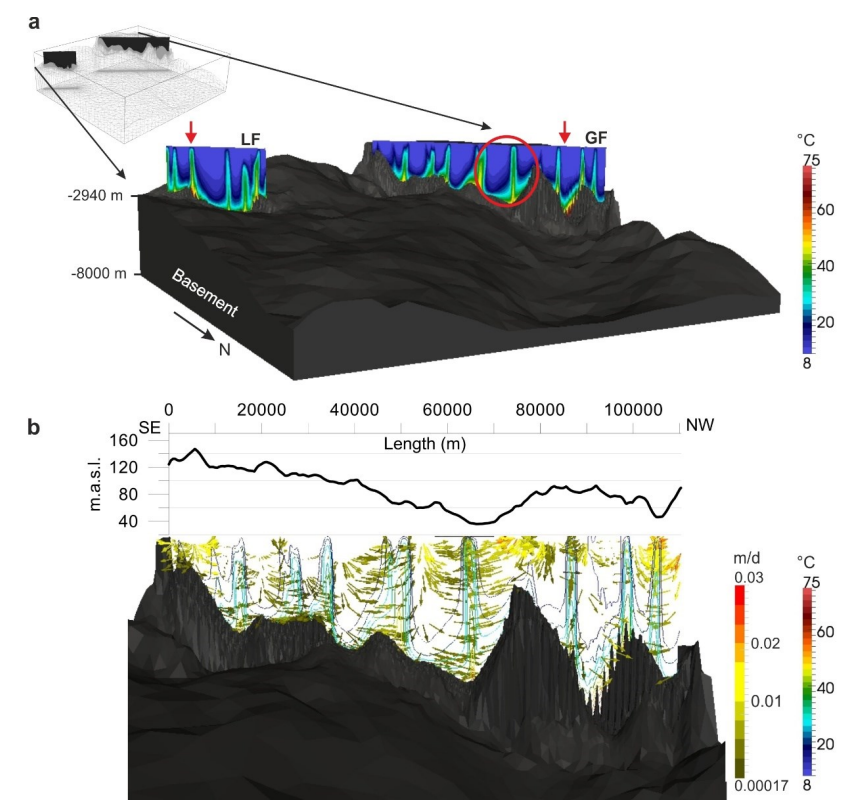

Figure 7. (a) Temperature distribution along the fault planes in strike direction of the permeable Gardelegen (GF) and Lausitz faults (LF). Alternating hotter and colder domains characterize the thermal state within both fault zones. The red arrows indicate the location of two vertical cross sections shown in Fig. 8. The cross sections cut through the faults zones parallel to the $\mathrm{N}-\mathrm{S}$ axis. The red circle shows the location of the close-up of Fig. 10 (vertical exaggeration: $7: 1$ ). (b) Combination plot of fluid velocity vectors (length of vectors are not scaled) and isotherms along the entire length of the Gardelegen Fault assumed permeable (model 3). At the top, the topographic elevation used as a proxy for hydraulic head boundary condition at the surface is delineated along the trace of the fault zone. Down- and upward-oriented flow are initiated by hydraulic head gradients but may be enhanced by a convective fluid flow component.

The temperature distribution and corresponding fluid dynamics within both faults can be spatially correlated with the topographic elevation along the fault zones (Fig. 7b). At areas of high topographic elevation, recharge areas, cold water $\left(8^{\circ} \mathrm{C}\right)$ is forced to enter from the surface of the model due to the hydraulic boundary conditions imposed. According to Darcy's law (see Eq. 2 in Appendix A), steep hydraulic head gradients result in higher flow velocities of infiltrating water. Due to the higher permeability of the fault zone (Table 2), fluid can easily flow downwards, being fast enough to result in the observed cooling. Reaching deeper parts of the fault zone, the fluid is heated by thermal equilibration with the surrounding matrix system (its velocity diminishes with depth) and will rise upwards at specific areas following the distribution of the hydraulic head gradients. These hotter domains within the fault mainly correspond to areas of lower topographic elevation, discharge areas.

In conclusion, fluid motion within the fault is driven principally by fluid advection due to hydraulic head gradients 
imposed along the top boundary. Depending on the pressure and temperature conditions at depth, local upward movement of the fluid may be locally enhanced by buoyancy forces. However, thermally buoyant forces exert only a secondary contribution to the fluid movement, thus having a little impact on the resulting thermal field.

\subsection{Interaction between fault zones and surrounding sediments}

To analyse the temperature field and fluid behaviour across the fault zones, and to understand the interaction between fault zones and surrounding sediments, two representative vertical profiles are chosen. The first profile cuts through a recharge zone at the Gardelegen Fault (GF), whereas the second profile dissects a discharge area at the Lausitz fault zone (LF) (Fig. 7a). Based on these two profiles, the results are visualized by focusing only on the fault zone areas. For both sections, both temperature distribution and flow field are illustrated for models 1, 2 and 3 (Figs. 8a-f and 9a-f). These profiles should be considered as representative for the other parts of the fault zones characterized by similar hydraulic conditions.

\subsubsection{Recharge area - Gardelegen fault zone}

\section{Model 1}

An initial consideration of the temperature distribution for model 1 reveals relatively flat isotherms in the area of the pre-Permian basement, displaying somewhat cooler temperatures in the south (Fig. 8a). Convex upward-shaped isotherms characterize the central part of the profile in the narrow transition zone between the deep and the shallow Rotliegend aquifer within a transition region extending between the prePermian basement and the Permian Zechstein. Within the Permian Zechstein layer, the isotherms distinctively bend upwards. This thermal anomaly indicates locally higher temperatures in the salt decreasing in the surrounding sediments.

Flat isotherms in the area of the pre-Permian basement reflect conductive heat transfer through this hydraulically impermeable layer. In addition, its higher thermal conductivity leads to an efficient heat transfer towards the surface. In the south, the basement is nearly exposed at the surface and it is not covered by insulating sediments. Due to its special geological setting, reduced temperatures are observed. This cooling trend reflects the thermal signature already observed in the regional thermal field along the southern margin of the study area (Fig. 5a and d).

The observed thermal anomaly throughout the Permian Zechstein salt is caused by thermal refraction, triggered by the sharp contrast between the thermally highly conductive salt and the low thermal conductivity of the surrounding sediments. Because the salt acts as a heat chimney, conductively transferring the heat towards the surface, it results in higher temperatures in the salt than within the surrounding less conductive sediments.

So far, the results demonstrate that conductive heat transfer decisively shapes the local thermal field through the thick pre-Permian basement and the Permian Zechstein, both impermeable to fluid flow and thermally more conductive than the surrounding sediments (Table 1).

In the shallow Cenozoic, Mesozoic and Buntsandstein aquifers, fluid velocity vectors indicate a diverging regional flow at the vertical offset in the central part of the profile (marking the position of the Gardelegen Fault) (Fig. 8b). This flow pattern results from the location of the profile beneath a major recharge area where cold water enters into the model and flows into the shallow aquifer sediments following the regional groundwater flow.

In the Rotliegend aquifer, fluid velocity vectors indicate regional flow from north to south. They also display a hydraulic connection of reduced velocities $\left(\sim 1 \times 10^{-6} \mathrm{~m} \mathrm{~d}^{-1}\right)$ within the narrow transition domain between the deep and shallow Rotliegend aquifer. Due to the adjacent impermeable basement, fluid flows upward following the geometry of the basement and flanking Zechstein salt layer. Upward flow of heated fluid leads to the observed upward-bent isotherms across this transition domain (Fig. 8a). By entering the shallow Rotliegend aquifer, fluid locally mixes with the regional flow.

\section{Model 2}

The thermal field for model 2 shows only weak disturbances in the fault zone area with respect to the case previously described (Fig. 8c). Compared to the thermal field of the nofault model 1 (Fig. 8a), only a slight temperature increase (max. $6^{\circ} \mathrm{C}$ ) can be distinguished in the domain of the hydraulic connection between the shallow and deep Rotliegend aquifer. Moving to the fluid velocity results (Fig. 8d), the results nicely show that fluid cannot enter the fault zone. Instead, fluid flow is redirected along the impermeable structure with very low fluid velocities $\left(\sim 1 \times 10^{-10} \mathrm{~m} \mathrm{~d}^{-1}\right)$ and flows laterally into the aquifers with increased velocities $\left(\sim 1 \times 10^{-8}-1 \times 10^{-6} \mathrm{~m} \mathrm{~d}^{-1}\right)$. Generally, fluid flow direction and fluid velocities are similar to the flow field of the no-fault model 1 within the aquifer systems (cf. Fig. 8b).

The presence of a tight fault has only a minor influence on the flow dynamics. Indeed, neither the fluid velocity in the surrounding sedimentary layers nor the fluid direction appears to change in the vicinity of the fault zone when compared to the no-fault model 1 (Fig. 8b). Very low fluid velocities along the fault-matrix boundary and spatially limited influence of the fault zone result in no remarkable influence on the thermal field. A minor temperature difference between the two models results from the locally disturbed fluid flow at the fault offset which marks the transition between shallow and deep Rotliegend aquifer. 

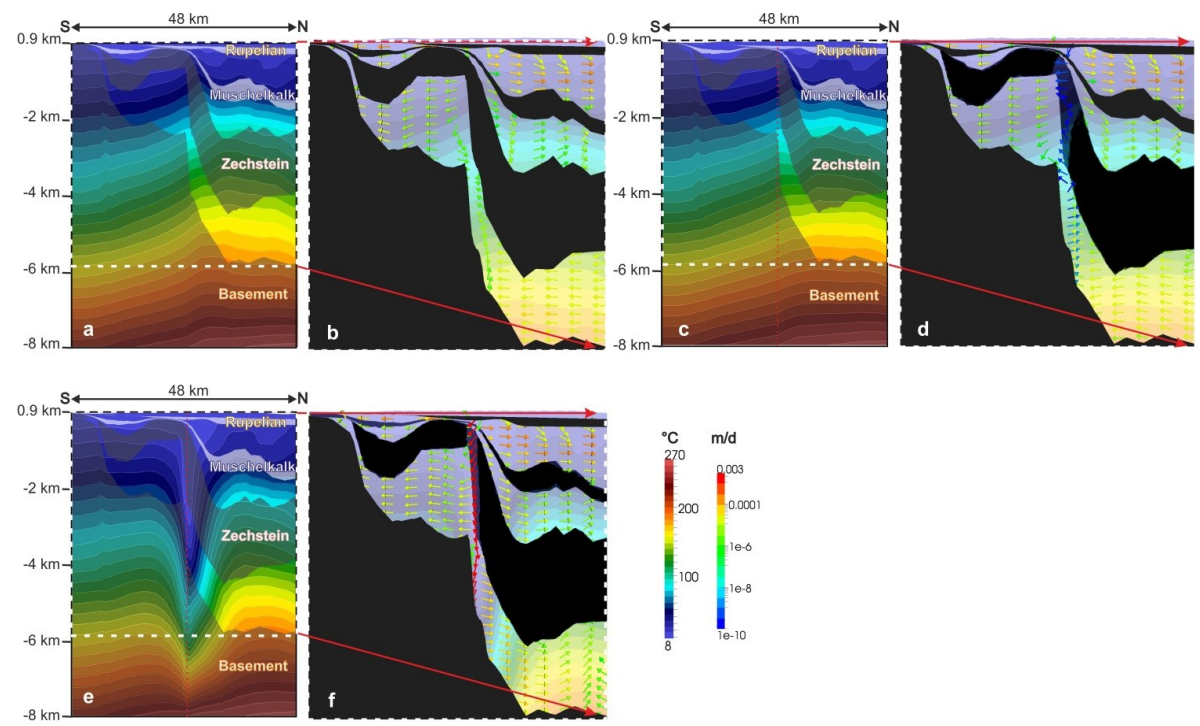

Figure 8. N-S cross section through the northwestern part of the Gardelegen fault (GF) plane (the location of the cross section is outlined in Fig. 7a by the red arrow on the right-hand side). In the combination plots of temperature distribution and fluid velocity vectors (b, $\mathbf{d}, \mathbf{f})$, the lengths of the fluid velocity vectors are non-scaled and the temperature distribution is shown with reduced intensity in the background. (a) Temperature distribution for model 1 in which no faults are integrated. The almost flat character of the isotherms reflects the diffusive nature of conductive heat transfer throughout the impermeable pre-Permian basement. Isotherm deflection is only present where the conductive Zechstein salt is thick. (b) Fluid velocity vectors and temperature distribution for the no-fault model 1 indicating horizontal flow in the upper aquifers. Predominantly upward directed flow only occurs where a hydraulic connection exists between the shallow and the deep Rotliegend aquifer. (c) Temperature distribution for the model 2 in which the fault zones are integrated as impermeable structures. The position of the fault zone is displayed by the dotted red line. Only a slight temperature increase is observed at the offset between shallow and deep Rotliegend aquifer when compared to the no-fault model. (d) Fluid velocity vectors and temperature distribution for the impermeable fault model 2. Very low fluid velocities are evident along the fault, and the communication of shallow and deep Rotliegend aquifers is inhibited. Apart from that, within the surrounding aquifer sediments, fluid direction and fluid velocities are similar to the no-fault model 1. (e) Temperature distribution for the permeable fault model 3. A strong cooling is induced by the permeable fault zone cutting through the central part of the profile (indicated by the dotted red line). (f) Fluid velocity vectors and temperature distribution for fault model 3 displaying a fast downward-oriented flow inside the permeable fault zone and a lateral outflow into the surrounding aquifer sediments.

\section{Model 3}

Considering the fault zone as more permeable than the neighbouring sedimentary layers significantly changes both the thermal field (Fig. 8e) and the fluid circulation pattern (Fig. 8f) compared to the no-fault case (Fig. 8a and b). A negative thermal anomaly characterizes the thermal state in which the isotherms are sharply bent downward, indicating a strong cooling in the central domain of the fault plane. This pattern continues to greater depth but weakens towards the pre-Permian basement. Along both sides of the fault zone, a step-wise increase in modelled temperatures is visible at a distance of approximately $3 \mathrm{~km}$ from the fault plane. The corresponding fluid velocity vectors display a fast downwardoriented flow (of up to $0.003 \mathrm{~m} \mathrm{~d}^{-1}$ ) in the central part of the fault zone (Fig. 8f). Along the fault flanks, velocity vectors indicate a lateral fluid outflow from the fault zone into the permeable sediments of the different aquifer systems. While this lateral flow direction is maintained throughout the aquifer systems, the fluid velocity gradually decreases with increasing distance from the fault zone.
The observed fast downward-oriented flow in the fault zone explains the strong cooling observed at the same location. The relatively strong temperature drop is induced by the surface water inflow $\left(8^{\circ} \mathrm{C}\right)$ from the upper tip of the fault zone located beneath a major recharge area (cf. Fig. 7b). The higher permeability of the fault zone translates to high fluid velocities and downward-oriented flow through the fault zone. Reaching the lower tip of the fault, fluid cannot penetrate the impermeable pre-Permian basement. Within this layer, heat is transferred only by conduction. This transition between heat transfer processes is displayed by the weakening of downward-bent isotherms throughout the pre-Permian basement layer.

As a possible further consequence of the fast downward flow in the fault zone, fluid penetration occurs from the fault zone into the surrounding aquifers. The gradual decrease of the fluid velocities with increasing distance from the fault mainly results from the differences in the permeability of the fault and of the surrounding aquifers, and the permeability decreases from the fault zone to the sedimentary layers 
(Tables 1 and 2). Accordingly, the velocity of modelled lateral flow may vary within each aquifer.

The induced lateral outflow from the fault zones into the surrounding aquifers is also reflected by an increased range of influence of the permeable fault zones in the regional temperature distribution at -1000 and $-3000 \mathrm{~m}$ depth as described previously (cf. Fig. 5c and f).

The shallow and deep Rotliegend aquifers are still hydraulically connected through offset by the presence of the permeable fault, which considerably changes fluid pathways and fluid velocities. Most significantly, the direction of fluid flow is reversed along the offset, changing from slowly upward flow in the no-fault case (Fig. 8b) to fast downwardoriented flow in the permeable fault zone (Fig. 8f). As a further consequence of the downward flow in the fault, fluid flow direction is inverted within the deep Rotliegend aquifer sediments.

In summary, when located beneath a major recharge area, the highly permeable fault is characterized by downwardoriented fluid flow which induces net cooling in the permeable fault zone. In the adjacent aquifers, fluid flow is directed away from the fault zone and varies in magnitudes in relation to the specific permeability values of the individual sedimentary layers.

\subsubsection{Discharge area - Lausitz fault zone}

\section{Model 1}

In the no-fault model 1, flat and almost horizontal parallel isotherms characterize the area of the thick pre-Permian basement, whereas slightly disturbed isotherms can be observed within the Zechstein salt (Fig. 9a). In the Mesozoic aquifer, the isotherms indicate slightly decreased temperatures below the Rupelian windows in the northern part of the profile.

The geometric distribution of the isotherms within the basement points to conductive heat transfer through this impermeable layer. Thermal refraction is reflected by the pattern of modelled isotherms throughout the Zechstein salt and surrounding sediments. Cooler temperatures in the Cenozoic and Mesozoic aquifers are induced by the inflow of cold surface water through the Rupelian windows. Beneath the latter hydraulic window, fluid velocity vectors indicate vigorous fluid flow (Fig. 9b). In the deeper Buntsandstein and Rotliegend aquifers, a predominant lateral fluid flow direction from north to south is displayed by the fluid velocity vectors. This regional trend is only disturbed at the narrow transition between deep and shallow Buntsandstein and Rotliegend aquifers (marking the location of the Lausitz fault zone) where the basement and Zechstein salt are closest.

The regional flow direction from north to south is induced by the location of the profile at a discharge area, adjacent to a major recharge zone in the north (cf. Fig. 1b). Due the steep hydraulic head gradient (connecting the discharge with the recharge area), enhanced fluid inflow occurs from the north and results in the regional north-south-directed flow pattern. At the narrow hydraulic connection between deep and shallow Buntsandstein and Rotliegend aquifers, fluid flows upwards by following the relief of the impermeable basement and Zechstein salt layers. By reaching the shallow parts of the Buntsandstein and Rotliegend aquifers, fluid mixes with the shallow aquifer fluids.

\section{Model 2}

The isotherm pattern for model 2 (Fig. 9c) is very similar to the thermal field of the no-fault model 1 (Fig. 9a) and confirms previous conclusions made on the regional temperature field (Fig. 5b, e) and on the temperature distribution around the Gardelegen fault zone (Fig. 8c). In the shallow Cenozoic and Mesozoic aquifers, fluid velocity vectors resemble the regional trend as observed in no-fault model 1 (Fig. 9d). Along the fault zone, fluid is characterized by very low fluid velocities $\left(\sim 1 \times 10^{-10} \mathrm{~m} \mathrm{~d}^{-1}\right)$. Fluid flow is locally disturbed and redirected north of the fault zone within the deeper part of the Buntsandstein aquifer. Throughout the deeper part of the Rotliegend aquifer, the regional north-south flow pattern is dominant. Compared to the no-fault model 1, fluid flows from the shallow Buntsandstein and Rotliegend sediments towards the fault zone and no fluid mixing can be observed at the narrow transition.

Along the fault zone, fluid flow is characterized by very low fluid velocities due to impermeable conditions of the latter. Because fluid cannot discharge into the fault zone, it is redirected in the adjacent aquifer sediments. No hydraulic connection exists between the shallow and deep Buntsandstein and Rotliegend aquifer domains. Therefore, no mixing occurs between the shallow and deep aquifer. But fluid flows laterally from the shallow Buntsandstein and Rotliegend sediments towards the impermeable fault zone.

In conclusion, the results for model 2 confirm a spatially limited impact of a tight fault zone which leads to an almost unchanged temperature field when compared to the no-fault scenario. The effects of the impermeable fault zone are only local and result in a disturbance of the flow field near the fault zone which inhibits any hydraulic communication between shallow and deep aquifers which are offset at depths by the fault (Buntsandstein and Rotliegend).

\section{Model 3}

In the case of a permeable fault (model 3), significant differences can be observed in the thermal field compared to the models 1 and 2 (Fig. 9e). In the central part of the fault zone, the isotherms are bent upwards, revealing locally increased temperatures, which gradually decrease within the underlying pre-Permian basement. At the fault-sediment interface, temperatures are decreased (e.g. $75^{\circ} \mathrm{C}$ at $-3500 \mathrm{~m}$ 

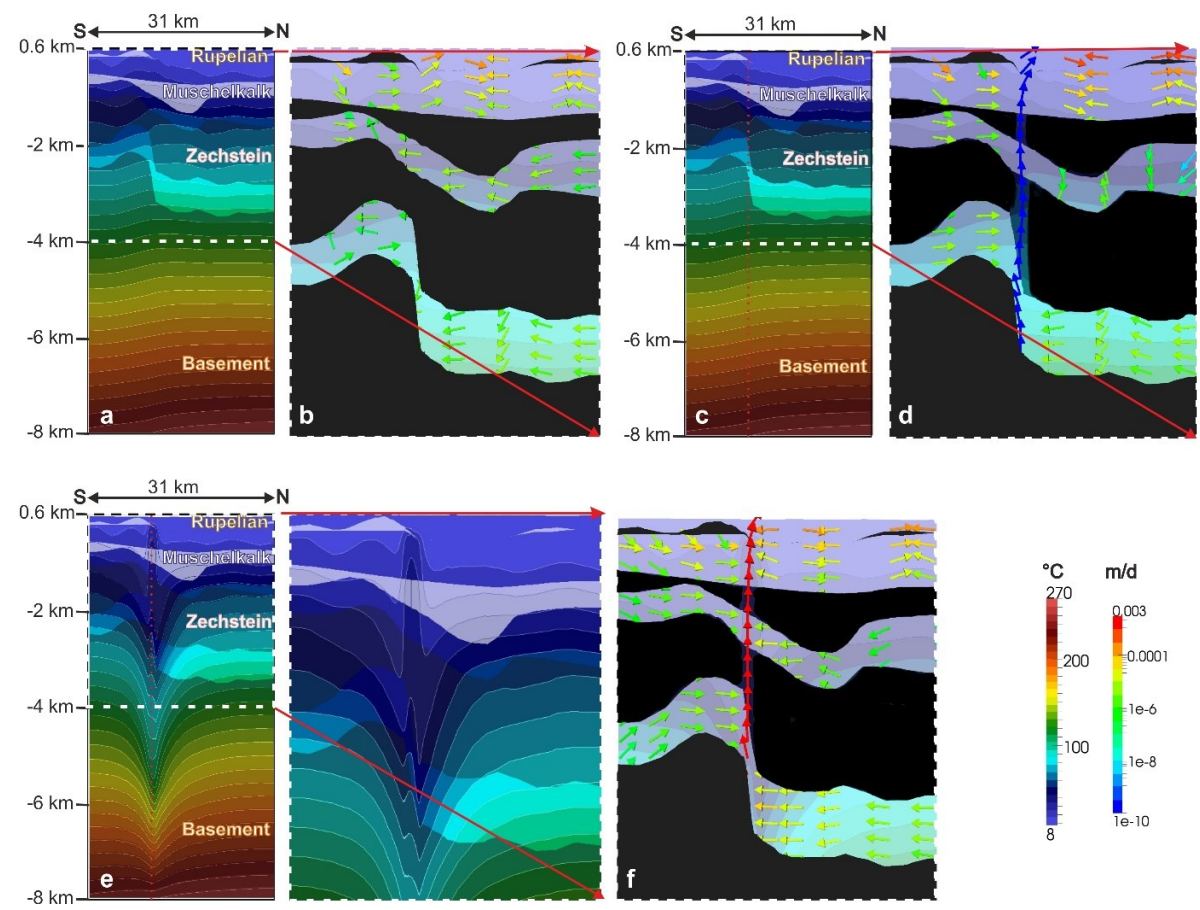

Figure 9. N-S cross section through the southeastern part of the Lausitz fault (LF) plane (the location of the cross section is outlined in Fig. 7a by the red arrow on the left-hand side). In the combination plots of temperature distribution and fluid velocity vectors (b, $\mathbf{d}, \mathbf{f})$, the lengths of the fluid velocity vectors are non-scaled and the temperature distribution is shown with reduced intensity in the background. (a) Temperature distribution for model 1 in which no faults are implemented. The isotherms indicate a net cooling effect in the shallow Cenozoic and Mesozoic aquifers, induced by unhampered cold water inflow through the Rupelian windows in the northern part of the profile. (b) Fluid velocity vectors and temperature distribution for the no-fault model 1. The regional flow direction is from north to south. At the offset, where the basement, Zechstein and Buntsandstein layers are in close contact, fluid mixing occurs within the aquifers. (c) Temperature distribution for the impermeable fault model 2. The position of the fault zone is displayed by the dotted red line. The isotherm pattern closely resembles the thermal field for the no-fault model 2. (d) Fluid velocity vectors and temperature distribution for model 2. Because the fault zone acts as a fluid flow barrier, no hydraulic connection exists between deep and shallow aquifers at the offset. (e) Temperature distribution for the permeable fault model 3. The temperature zoom on the right shows that the isotherms are bent upwards inside the fault zone, indicating a temperature increase down to a depth of $\sim-4000 \mathrm{~m}$. (f) Fluid velocity vectors and temperature distribution for the permeable fault model 3. Fast upward-oriented flow characterizes the central part of the fault zone, whereas lateral fluid advection is observed from surrounding sediments towards the fault with reduced fluid velocities.

depth) compared to the temperatures within the surrounding aquifer sediments $\left(\sim 110^{\circ} \mathrm{C}\right.$ at -3500 depth $)$.

Fluid velocity vectors display a fast upward directed flow in the central part of the fault zone $\left(\max .1 \times 10^{-4} \mathrm{~m} \mathrm{~d}^{-1}\right.$ ) (Fig. 9f). Similar to model 1, fluid velocity vectors display vigorous fluid flow below the Rupelian windows within the shallow Cenozoic and Mesozoic aquifers and a regional flow from north to south in the deeper Buntsandstein and Rotliegend aquifers north of the permeable fault zone. In general, fluid inflow occurs from all surrounding aquifer sediments into the fault zone $\left(\sim 1 \times 10^{-6}-1 \times 10^{-4} \mathrm{~m} \mathrm{~d}^{-1}\right)$.

Fast upward-oriented flow reflects a local temperature increase within the fault zone (Fig. 9e). Within the pre-Permian basement, fluid flow is impeded and the heat is transferred by conduction only. Within the fault zone, fluid flows upwards following the hydraulic head potential (cf. Fig. 7b).
The temperature drop next to the fault zone is induced by an inflow of colder fluid $\left(8-10^{\circ} \mathrm{C}\right)$, which has been initially transported downwards the fault zone below a recharge area (cf. Figs. 7b, 8f), laterally impressed into the aquifer sediments (Fig. 8f), and from there has been finally redirected towards the fault zone. This lateral inflow from the aquifer into the fault zone is induced the by high permeability contrast between fault and surrounding sediments (Tables 1 and 2). At the fault-sediment interface thermal equilibration takes place, thus resulting in the observed overall temperature gradient between the fault and the sedimentary covers. The main result of this complex dynamics is reflected in the presence of a cone of depression in the temperature centred at the upflow domain within the flow, the extent of which increases with depth due to larger temperature gradients between the fault and the sediments reaching greater depth levels. 

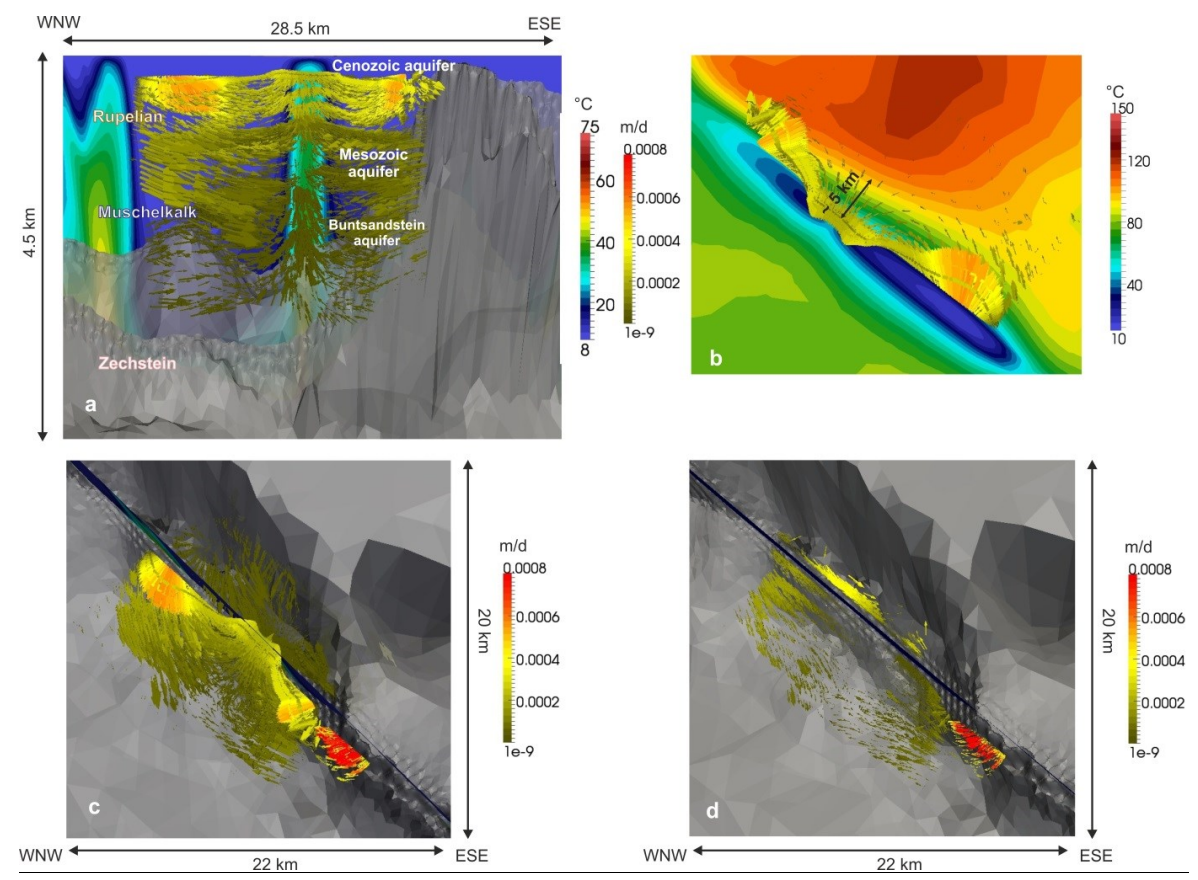

Figure 10. (a) Close-up of the 3-D flow field around the permeable fault zone (model 3) above the Permian Zechstein layer (grey-shaded). The temperature distribution along the strike of the Gardelegen fault zone is displayed in the background. Location of the zoom is delineated in Fig. 7a by the red circle. The velocity vectors clearly indicate flow from the surrounding aquifers towards the permeable fault zone. The lengths of the fluid velocity vectors are non-scaled. (b) Top view of Fig. 10a zooming in on the temperature distribution at $-3000 \mathrm{~m}$ depth (position is outlined in Fig. $5 \mathrm{f}$ by a black rectangle) indicating the range of influence of the fault on the flow and thermal field. (c) Top view on the 3-D flow field around the permeable fault zone (model 3) for the same location as in Fig. 10a and b. Fluid advection towards the fault zone is displayed by the vectors, and is induced by the high permeability contrast between fault and neighbouring sedimentary layers. (d) Top view on the 3-D flow field around the impermeable fault zone (model 2) for the same location as in the previous subfigures. Fluid flow in the surrounding sediments is redirected parallel to the fault zone due to the impermeable nature of the fault.

In conclusion, upward-oriented fluid flow induces higher temperatures in the permeable fault zone. Fluid inflow is observed from the less permeable surrounding aquifers into the permeable Lausitz fault zone located beneath a major discharge area.

\subsubsection{3-D sections}

To get a final overview of the fluid behaviour around both fault zones, 3-D close-up views are shown for the two fault models (model 2 and model 3).

Figure 10a shows a close-up plot of the flow field in the sedimentary layers above the Zechstein salt layer around the permeable Gardelegen fault zone (model 3). The temperature field along the strike direction of the Gardelegen fault zone is shown in the background.

Velocity vectors indicate increased fluid inflow from the top of the section into the Cenozoic aquifer with highest velocities $\left(4 \times 10^{-4}-8 \times 10^{-4} \mathrm{~m} \mathrm{~d}^{-1}\right)$ down to the depth level of the Rupelian aquitard. Throughout the Mesozoic aquifer, fluid velocities are reduced $\left(\sim 2 \times 10^{-4}-4 \times 10^{-4} \mathrm{~m} \mathrm{~d}^{-1}\right)$ compared to the shallow Cenozoic aquifer. Below the Muschel- kalk aquitard, fluid velocities further decrease down to $\sim 1 \times 10^{-9} \mathrm{~m} \mathrm{~d}^{-1}$ within the Buntsandstein aquifer.

While fluid velocities gradually drop with depth due to decreasing permeabilities of the aquifers (Table 1) and aquitards, modelled fluid flow shows a consistent direction within the whole aquifer systems. A downward-oriented flow is displayed in the shallow Cenozoic aquifer. Downward flow occurs in areas where cooler temperatures $\left(\sim 8-25^{\circ} \mathrm{C}\right)$ characterize the internal part of the fault zone (in the background, Fig. 10a). Fluid is then redirected towards the fault zone in all aquifers due to the high permeability of the latter. Finally, upward-oriented flow can be seen in areas where higher temperatures $\left(\sim 25-50{ }^{\circ} \mathrm{C}\right)$ are present in the fault zone.

Looking from top of the 3-D image in map view, we can conclude that the fault zone influences the fluid movement and the temperature field in the surrounding sediments at $-3000 \mathrm{~m}$ depth within an influence radius of $\sim 5 \mathrm{~km}$ (Fig. 10b; cf. Fig. 5c and f).

Figure 10c and d show top views for the same 3-D block section as in Fig. 10a for the permeable fault model 3 and for the impermeable fault model 2, respectively. Fluid velocity vectors clearly reflect enhanced fluid advection from the surrounding sediments towards the permeable fault zone 
(Fig. 10c). By contrast, fluid cannot enter the impermeable fault zone (Fig. 10d). Furthermore, overall reduced fluid velocities characterize the flow in close proximity to the fault zone $\left(\sim 1 \times 10^{-9}-4 \times 10^{-4} \mathrm{~m} \mathrm{~d}^{-1}\right)$ where the fluid flow is deviated along the same structure. The range of influence is restricted to a distance of $\sim 1 \mathrm{~km}$ on each side of the fault.

\section{Discussion and conclusions}

The investigation of fault zones with varying permeability by 3-D coupled fluid and heat transport simulations reveals a distinct local influence on the regional thermal field and fluid system for the different permeability configurations considered.

\subsection{Regional thermal field without faults}

The regional temperature distribution at different depth levels is the result of superposed thermal effects generated by the complex interaction between aquifers and aquitards of varying thickness and different fluid and heat transport processes, i.e. advection, buoyant flow and heat conduction.

Advective processes strongly affect the shallow thermal field in the Cenozoic and Mesozoic aquifers down to a maximum penetration depth of approximately $-3000 \mathrm{~m}$. Where the Rupelian clay is missing, inflow of cold water from the top surface, as triggered by the upper boundary conditions, induces a pronounced cooling in the Mesozoic aquifer. Three-dimensional models of coupled fluid and heat transport of the NEGB have already shown that pressure forces triggered by local topographic gradients may be strong enough to induce a net cooling on the shallow aquifer system, whereby higher permeability of the corresponding layers promotes greater penetration depths of cold water (Kaiser et al., 2011).

Indications for convective flow in the shallower Mesozoic aquifer play an additional, though secondary, role in areas confined by a thick sequence of Rupelian clay, preventing inflow of cold water from the Cenozoic aquifer and shielding the influence of superficial hydraulic head gradient on the underlying Mesozoic aquifer (Noack et al., 2013).

Heat conduction through the thick pre-Permian basement and the Permian Zechstein (both impermeable to fluid flow but thermally higher conductive than the surrounding sediments), decisively shapes the local thermal field across the southern margin and in the vicinity of salt diapirs in the central basin.

\subsection{Influence of impermeable fault zones}

When implementing fault zones as low permeable structures, the temperature distribution resembles the regional thermal field modelled when no faults are considered. The influence of impermeable faults on the flow field is local, limited to the fault zone itself and its close proximity. Fluid flow, both the direction and magnitudes of fluid velocity, within the surrounding sediments is unaffected by the presence of a tight fault. At the fault zone, fluid flow is deviated from the sediments with very low velocities. Acting as hydraulic barriers, fault zones prevent a lateral fluid inflow. Fluid cannot be transmitted through the fault zones resulting in very low fluid velocities, thus leaving conduction as the predominant heat transport process. Due to low fluid velocities and a spatially limited influence of the fault, no remarkable influence on the thermal field can be observed.

\subsection{Influence of permeable fault zones}

Highly permeable fault zones (model 3) may locally exert a considerable influence on the thermal field. Along both permeable fault zones distinctly cooler temperatures than in its surroundings characterize the thermal field, expressed by an alternating thermal signature. The range of influence of the permeable fault zones extends over a distance of $\sim 2.4$ $8.8 \mathrm{~km}$ in $-1000 \mathrm{~m}$ depth and $\sim 6-14 \mathrm{~km}$ in $-3000 \mathrm{~m}$ depth. Inside the fault zones, a net cooling effect is induced by relatively fast downward flow. Triggered by fluid advection due to hydraulic head gradients and enhanced by the high permeability of the fault zones, cold water can easily flow downwards, generating the cooling.

The observed cooling alternates with higher thermal anomalies through upward directed flow below discharge areas, which may be locally enhanced by buoyancy forces having a secondary effect on both the hydrodynamics and thermal field.

\subsection{Interaction between fault zones and surrounding sediments}

The fluid behaviour in the sediments surrounding both fault zones is principally controlled by existing hydraulic head gradients and by the permeability of the fault zones. Modelled fluid flow and thermal field within the surrounding sediments are locally influenced by the presence of the permeable fault zones along their strike direction. Across these fault zones, the thermal field and fluid flow are affected by the thickness and permeability of the sedimentary layers adjacent to the faults.

Below recharge areas and adjacent steep hydraulic gradients, downward-oriented flow inside the fault zones in turn affects the temperature and flow field in the surrounding sediments. Fast downward flow impresses a lateral fluid discharge into the surrounding aquifers. Below discharge areas, the regional flow pattern induced by topographic gradients combined with the higher fault permeability leads to lateral fluid inflow from the aquifers towards the fault zones. Both the lateral outflow from faults into the aquifers below recharge areas and the lateral inflow from aquifers into the faults below discharge areas clearly demonstrate the dynamic interaction between surrounding sediments and fault zones. 
Outside the range of influence of the fault zones, the temperature distribution is controlled by different heat transport processes closely linked to the distribution of the aquifers and aquitards.

\subsection{Inferences for geothermal applications}

The fault model outcomes provide valuable inferences on fault zone behaviour and its impact on the surrounding groundwater circulation and thermal field, which might be useful for geothermal energy exploration.

The study has highlighted two major implications for geothermal applications.

1. Impermeable fault zones have little effect for the thermal field and very locally deviate the flow field in the sediments next to the faults. Therefore, this setting would be an unfavourable place to drill a geothermal well.

2. Drilling a geothermal well into or in close proximity to a permeable fault zone would be more prospective in the shallow part of the model domain (up to $\sim 450 \mathrm{~m}$ depth), where rising warm fluids are in concert with high permeability of the faults. These spots of rising warm water are locally restricted but temperatures are increased (up to $15^{\circ} \mathrm{C}$ compared to the thermal field without faults). By contrast, domains of colder temperatures next to permeable sediments are the most unfavourable areas for geothermal utilization.

In the deeper Buntsandstein and Rotliegend aquifers the temperature distribution along permeable fault zones is affected by the net cooling effect propagating downward below major recharge areas and steep hydraulic head gradients. This net cooling effect is enhanced by the high permeability of the fault zones. Below adjacent discharge areas, a temperature increase in the fault zones is observed down to a depth of $\sim-4000 \mathrm{~m}$ due to upward-oriented flow.

In summary, the best place to drill a prospective geothermal well would need to be chosen with care, as two conditions should be fulfilled: (1) enhanced inflow of warm and deep water into the fault and (2) a rising branch of heated fluid within the fault zone.

\subsection{Model limitations and outlook for future studies}

Some limitations of the study presented include (1) the structural resolution of the model, (2) the physical fault zone representation and (3) the choice of hydraulic boundary conditions adopted along the top boundary.

1. The structural resolution of the model in particular concerns the distribution of sedimentary layers in the proximity of the fault zones, as it has been concluded that the fluid flow in the surroundings may locally contribute to the fluid behaviour of the permeable fault. As the current study revealed that fault zones locally influence the thermal and fluid system, in a subsequent step, a higher resolution of the model could be achieved by a structural refinement and by focussing only on the areas around the fault zones by decreasing the model size considerably. This step, however, would also assume better constraints on physical rock properties for both the sedimentary and the fault zones (see also point 2 below).

2. As the two fault zones are represented as idealized, homogenously permeable/impermeable zones of a finite width, the modelled thermal and hydraulic pattern in the fault zones are first-order effects. In a realcase scenario, these effects might be more complex. Thus, the models may locally under/overestimate the absolute amplitude of the signal, which is nonetheless present. Further studies may consider a more heterogeneous composition of the fault zone, possibly consisting of a damage zone and a fault core. However, more detailed data would be required on the structure and composition of the Gardelegen and Lausitz fault zones. These could be beneficial for future studies aiming at a more quantitative assessment of their impact on the thermal and groundwater field. Local reservoir-scale models integrating more highly resolved structural data, information derived from boreholes, and in situ measurements may provide better constraints for the characterization of fault zones (e.g. Cacace et al., 2013; Blöcher et al., 2010). Better constraints on the hydraulic behaviour of fault zones may be provided by prospective integrated geophysical methods (e.g. magnetotellurics) that could help to discriminate between different endmember models. At present, a direct assessment of the hydraulic behaviour of faults by the determination of their orientation within the present-day stress field is not possible. This was reflected in the modelling approach followed, in which different end-member stress states have been tested. Given the state of the art of available information, this study represents the best quantitative approach so far to characterize the thermal and hydraulic behaviour of major fault zones in a basin-scale model.

3. The cooling observed in the permeable fault zone and in the Mesozoic aquifer may overestimate the influence of forced convection processes due to the crude boundary setting adopted. Future studies are needed that integrate more realistic information on recharge rates and may be additionally improved by a dynamic coupling with surface water transport modelling.

This study is the first attempt to investigate the impact of major fault zones on a 3-D basin scale for the coupled fluid and heat transport in the Brandenburg region. The simulation outcomes provide new insights into the dynamic mechanisms 
that control the fluid behaviour and thermal evolution of fault zones with varying permeability in the context of a complex hydrogeological setting. While the lateral influence of a $1 \mathrm{~km}$ wide fault zone is rather limited with respect to the neighbouring sediments, temperature variations within the fault zone may be significant, thus having interesting application for issues related to geothermal exploration.

Acknowledgements. This work is part of project GeoEn and has been funded by the German Federal Ministry of Education and Research within the programme "Spitzenforschung in den neuen Ländern" (BMBF grant 03G0671A/B/C).

Björn Lewerenz and Björn Kaiser are thanked for helpful computational support and Peter Klitzke for his contributions to visualization. We thank Michael Schneider, the anonymous reviewer and Rüdiger Schulz for their helpful and constructive comments that helped to improve the quality of the manuscript. All numerical results are illustrated by ParaView, an open-source, multi-platform and visualization application.

The service charges for this open access publication have been covered by a Research Centre of the Helmholtz Association.

Edited by: R. Schulz

Reviewed by: M. Schneider and one anonymous referee

\section{References}

Alt-Epping, P. and Zhao, C.: Reactive mass transport modelling of a three-dimensional vertical fault zone with a finger-like convective flow regime, J. Geochem. Explor., 106, 8-23, 2010.

Amante, C. and Eakins, B. W.: ETOPO1 1 Arc-Minute Global Relief Model: Procedures, Data Sources and Analysis, NOAA Technical Memorandum NESDIS NGDC-24, 19 pp., 2009.

Bächler, D., Kohl, T., and Rybach, L.: Impact of graben-parallel faults on hydrothermal convection - Rhine Graben case study, Phys. Chem. Earth, 28, 431-441, 2003.

Baietto, A., Cadoppi, P., Martinotti, G., Perello, P., Perrochet, P., and Vuataz, F.-D.: Assessment of thermal circulations in strikeslip fault systems: the Terme di Valdieri case (Italian western Alps), Geol. Soc., London, Special Publications 299, 317-339, doi:10.1144/SP299.19, 2008.

Balling, N., Kristiansen, J. I., Breiner, N., Poulsen, K. D., Rasmussen, R., and Saxov, S.: Geothermal measurements and subsurface temperature modelling in Denmark, GeoSrifter, Department of Geology Aarhus University, 16, 1981.

Barton, C. A., Zoback, M. D., and Moos, D.: Fluid flow along potentially active faults in crystalline rock, Geology 23, 683-686, 1995.

Bayer, U., Scheck, M., and Koehler, M.: Modeling of the 3-D thermal field in the northeast German Basin, Geol. Rundsch., 86, 241-251, 1997.

Bense, V. F., Person, M. A., Chaudhary, K., You, Y., Cremer, N., and Simon, S.: Thermal anomalies indicate preferential flow along faults in unconsolidated sedimentary aquifers, Geophys. Res. Lett., 35, L24406, doi:10.1029/2008GL036017, 2008.
Bjørlykke, K.: Subsurface water and fluid flow in sedimentary basins, Petroleum Geoscience: From Sedimentary Environments to Rock Physics, 259-279, Springer, Heidelberg, doi:10.1007/978-3-642-02332-3_10, 2010.

Blöcher, M. G., Zimmermann, G., Moeck, I., Brandt, W., Hassanzadegan, A., and Magri, F.: 3D Numerical Modeling of Hydrothermal Processes during the Lifetime of a Deep Geothermal Reservoir, Geofluids, 10, 406-421, 2010.

Cacace, M., Bayer, U., and Marotta, A. M.: Strain localization due to structural in-homogeneities in the Central European Basin, Int. J. Earth Sci. (Geol. Rundsch.), 97, 899-913, 2008.

Cacace, M., Blöcher, G., Watanabe, N., Moeck, I., Börsing, N., Scheck-Wenderoth, M., Kolditz, O., and Huenges, E.: Modelling of fractured carbonate reservoirs-outline of a novel technique via a case study from the Molasse Basin, southern Bavaria (Germany), Environ. Earth Sci., 70, 3585-3602, doi:10.1007/s12665013-2402-3, 2013.

Cherubini, Y., Cacace, M., Scheck-Wenderoth, M., Moeck, I., and Lewerenz, B.: Controls on the deep thermal field - implications from 3-D numerical simulations for the geothermal research site Groß Schönebeck, Environ. Earth Sci., 70, 36193642, doi:10.1007/s12665-013-2519-4, 2013.

Diener, J., Katzung, G., and Kühn, P. et al.: Geothermie-Atlas der Deutschen Demokratischen Republik, Zentrales Geologisches Institut-ZGI-Berlin, 1984.

Diersch, H.-J. G.: FEFLOW Finite-Element Subsurface Flow and Transport Simulation System, User's Manual/Reference Manual/White Papers, Release 5.0. WASY GmbH, Berlin, 2002.

Garven, G., Bull, S. W., and Large, R. R.: Hydrothermal fluid flow models of stratiform ore genesis in the McArthur Basin, Northern Territory, Australia, Geofluids, 1, 289-311, 2001.

Hebig, K. H., Ito, N., Scheytt, T., and Marui, A.: Review: Deep groundwater research with focus on Germany, Hydrogeol. J., 20, 227-243, doi:210.1007/s10040-10011-10815-10041, 2012.

Kaiser, B. O., Cacace, M., Scheck-Wenderoth, M., and Lewerenz, B.: Characterization of main heat transport processes in the Northeast German Basin: Constraints from 3-D numerical models, Geochem. Geophy. Geosy., 12, Q07011, doi:10.1029/2011GC003535, 2011.

Lampe, C. and Person, M.: Advective cooling wihtin sedimentary rift basins - application to the Upper Rhinegraben (Germany), Mar. Pertol. Geol., 19, 361-375, 2002.

López, D. L. and Smith, L.: Fluid flow in fault zones: Analysis of the interplay of convective circulation and topographically driven groundwater flow, Water Resour. Res., 31, 1489-1503, 1995.

López, D. L. and Smith, L.: Fluid flow in fault zones: Influence of hydraulic anisotropy and heterogeneity on the fluid flow and heat transfer regime, Water Resour. Res., 32, 3227-3235, 1996.

Magri, F.: Derivation of the coefficients of thermal expansion and compressibility for use in FEFLOW (implementation code in $\mathrm{C}++$ ), White Pap., III, pp. 13-23, WASY GmbH Inst. for Water Resour. Plann. And Syst. Res., Berlin, 2004.

Magri, F.: Mechanismus und Fluiddynamik der Salzwasserzirkulation im Norddeutschen Becken: Ergebnisse thermohaliner numerischer Simulationen (Dissertation Thesis, Freie Universität Berlin), Scientific Technical Report STR05/12, GeoForschungsZentrum Potsdam, 131 pp., 2005.

Magri, F., Akar, T., Gemici, U., and Pekdeker, A.: Deep geothermal groundwater flow in the Seferihisar-Balçova area, Turkey: results 
from transient numerical simulations of coupled fluid flow and heat transport processes, Geofluids, 10, 388-405, 2010.

Marotta, A. M., Bayer, U., Thybo, H., and Scheck, M.: Origin of the regional stress in the North German basin: results from numerical modeling, Tectonophysics, 360, 245-264, 2002.

Maystrenko, Y., Bayer, U., and Scheck-Wenderoth, M.: Structure and Evolution of the Central European Basin System according to 3D modeling, DGMK Research Report, 577-2/2-1, 2010.

Noack, V., Cherubini, Y., Scheck-Wenderoth, M., Lewerenz, B., Höding, T., Simon, A., and Moeck, I.: Assessment of the presentday thermal field (NE German Basin) - Inferences from 3-D modeling, Chemie der Erde, 70, 47-62, 2010.

Noack, V., Scheck-Wenderoth, M., and Cacace, M.: Sensitivity of 3-D thermal models to the choice of boundary conditions and thermal properties - a case study for the area of Brandenburg (NE German Basin), Environ. Earth Sci., 67, 1695-1711, 2012.

Noack, V., Scheck-Wenderoth, M., Cacace, M., and Schneider, M.: Influence of moving fluids on the regional thermal field: results from 3-D numerical modelling for the area of Brandenburg (North German Basin), Environ. Earth Sci., 70, 3523-3544, 2013.

Pommer, H.: The control of faults on the thermal field in Northern Germany - Constraints from 2-D coupled numerical simulations, Department of Earth Sciences, Freie Universität Berlin, 69 pp., 2012.

Röckel, T. and Lempp, C.: Spannungszustand im Norddeutschen Becken, Erdöl Erdgas Kohle, 119, 73-80, 2003.

Roth, F. and Fleckenstein, P.: Stress orientations found in the NE Germany differ from the West-European trend, Terra Nova, 13, 289-296, 2001.

Scheck, M. and Bayer, U.: Evolution of the Northeast German Basin - inferences from a 3D structural model and subsidence analysis, Tectonophysics, 313, 145-169, 1999.

Scheck, M., Bayer, U., Otto, V., Lamarche, J., Banka, D., and Pharaoh, T.: The Elbe Fault System in North Central Europe a basement controlled zone of crustal weakness, Tectonophysics, 360, 281-299, 2002.
Scheck-Wenderoth, M. and Lamarche, J.: Crustal memory and basin evolution in the Central European Basin System - new insights from a 3D structural model, Tectonophysics, 397, 132165, 2005.

Scheck-Wenderoth, M., Krzywiec,P., Zühlke, R., Maystrenko, Y., and Froitzheim, N.: Permian to Cretaceous tectonics, in: The geology of Central Europe, T. McCann (Ed.), London, Geological society of London, 2, Mesozoic and Cenozoic, 999-1030, 2008.

Simms, M. A. and Garven, G.: Thermal convection in faulted extensional sedimentary basins: theoretical results from finite-element modeling, Geofluids, 4, 109-130, 2004.

Turcotte, D. L. and Schubert, G.: Geodynamics, Cambridge University Press, New York, 2002.

World Stress Map, www.world-stress-map.org/, 2000.

Yang, J.: Full 3-D numerical simulation of hydrothermal field flow in faulted sedimentary basins: Example of the McArthur Basin, Northern Australia, J. Geochem. Explor., 89, 440-444, 2006.

Yang, J., Large, R., and Bull, S.: Factors controlling free thermal convection in faults in sedimentary basins: implications for the formation of zinc-lead mineral deposits, Geofluids, 4, 1-11, 2004a.

Yang, J., Bull, S., and Large, R.: Numerical investigation of salinity in controlling ore-forming fluid transport in sedimentary basins: example of the HYC deposit, Northern Australia, Miner. Deposita, 39, 622-631, 2004b.

Zimmermann, G., Reinicke, A., Blöcher, G., Milsch, H., Gehrke, D., Holl, H.-G., Moeck, I., Brandt, W., Saadat, A., and Huenges, E.: Well path design and stimulation treatments at the geothermal research well GtGrSk4/05 in Groß Schönebeck, PROCEEDINGS, Thirty-Second Workshop on Geothermal Reservoir Engineering, Stanford University, Stanford, California, 22-24 January 2007, SGP-TR-183, 2007. 


\section{Appendix A}

The system of flow equations with variable fluid density $\rho^{\mathrm{f}}$ and viscosity $\mu^{\mathrm{f}}$ is given by the mass conservation of the fluid $-$

$$
\frac{\partial\left(\varepsilon \rho^{\mathrm{f}}\right)}{\partial t}+\nabla \cdot\left(\rho^{\mathrm{f}} q^{\mathrm{f}}\right)=\varepsilon Q_{\rho},
$$

where $\varepsilon$ is the porosity, $\rho^{\mathrm{f}}$ the mass density of the fluid, $\boldsymbol{q}^{\mathrm{f}}$ the specific discharge (Darcy's velocity), and $Q_{\rho}$ the sink-source mass term - as well as by the generalized Darcy law:

$\boldsymbol{q}^{\mathrm{f}}=-\boldsymbol{K}\left(\nabla h+\frac{\rho^{\mathrm{f}}-\rho_{0}^{\mathrm{f}}}{\rho_{0}^{\mathrm{f}}} \frac{\boldsymbol{g}}{|\boldsymbol{g}|}\right)$,

where $\boldsymbol{K}$ is the hydraulic conductivity tensor of the porous media given by $\boldsymbol{K}=\frac{\rho_{0}^{\mathrm{f}} g}{\mu^{\mathrm{f}}} \boldsymbol{k}$, with $\boldsymbol{k}$ being the permeability tensor and $g$ the gravity acceleration.

Equation (2) is written in terms of hydraulic head rather than pressure as the primary variable to conform to the mathematical formulation used in FEFLOW ${ }^{\circledR}$. Assuming thermal equilibrium between the porous medium and the fluid (i.e. $T f=T=T s$ ) and if density gradients are neglected, applying the law of energy conservation the following heat transfer equation results:

$(\rho c)_{\mathrm{fs}} \frac{\partial T}{\partial t}+\rho^{\mathrm{f}} c^{\mathrm{f}} \nabla \cdot\left(\boldsymbol{q}^{\mathrm{f}} T\right)-\nabla \cdot(\lambda \nabla T)=Q_{T}$,

with $(\rho c)_{\mathrm{fs}}$ being the bulk specific heat capacity of the fluid $(f)$ plus solid $(s)$ phase system, defined as

$(\rho c)_{\mathrm{fs}}=\left\lfloor\varepsilon \rho^{\mathrm{f}} c^{\mathrm{f}}+(1-\varepsilon) \rho^{\mathrm{s}} c^{\mathrm{s}}\right\rfloor$.
$Q_{T}$ is a heat source-sink function. $\lambda$ is the equivalent thermal conductivity tensor of the fluid and the porous medium; it takes both conductive (Fourier) and thermodispersive (mixing) effects into account. Accordingly, the equivalent thermal conductivity may be subdivided into its two components as

$\lambda=\lambda_{\mathrm{DISP}}+\lambda_{\mathrm{COND}}$

where the first term on the right-hand side of Eq. (5) is the thermodispersive term

$\lambda_{\text {DISP }}=\rho^{\mathrm{f}} c^{\mathrm{f}}\left[\alpha_{T} \sqrt{\left(q_{i}^{\mathrm{f}} q_{i}^{\mathrm{f}}\right)} \mathbf{I}+\left(\alpha_{L}-\alpha_{T}\right) \frac{q_{i}^{\mathrm{f}} q_{i}^{\mathrm{f}}}{\sqrt{\left(q_{i}^{\mathrm{f}} q_{i}^{\mathrm{f}}\right)}}\right]$

and the second term is the conductive one:

$\lambda_{\mathrm{COND}}=\varepsilon \lambda^{\mathrm{f}}+(1-\varepsilon) \lambda^{\mathrm{s}}$

In Eq. (6), $\alpha_{L}$ and $\alpha_{T}$ are respectively the longitudinal and transversal dispersion lengths, while $\lambda^{\mathrm{f}}$ and $\lambda^{\mathrm{s}}$ appearing in Eq. (7) represent the thermal conductivity of the fluid and solid phase and $\mathbf{I}$ is the unit matrix.

The balance Eqs. (2) and (3) are coupled by the fluid density according to an equation of state after Magri (2004) and Blöcher et al. (2010). 